\title{
Ground Magnetic, GPR, and Dipole-Dipole Resistivity for Landfill Investigation
}

\author{
Mohamed H. Khalil, Noha A. Hassan \\ Geophysics Department, Faculty of Science, Cairo University, Giza, Egypt \\ Email: nohaadel2010@live.com
}

Received 9 April 2016; accepted 27 June 2016; published 30 June 2016

Copyright (C) 2016 by authors and Scientific Research Publishing Inc.

This work is licensed under the Creative Commons Attribution International License (CC BY). http://creativecommons.org/licenses/by/4.0/

(c) () Open Access

\begin{abstract}
Ground magnetic, ground penetrating radar (GPR), and dipole-dipole resistivity were carried out to environmentally investigate a landfill. In this context, these geophysical techniques were conducted to identify the subsurface contents of the landfill, furthermore, specify any possible leakage and/or contamination in the study area. The ground-magnetic survey carried out in the study area comprised 31 profiles each $120 \mathrm{~m}$ in length. Different wavelength filters were applied to the measured data. Vertical derivative, downward continuation, apparent susceptibility, band-pass, and analytical signal filters separated successfully the shallow sources. Whereas, upward continuation and low-pass Gaussian filters isolated significantly the deep magnetic sources. 3D Euler deconvolution $(\mathrm{SI}=3)$ remarkably estimated the depths of the shallow sources $(0-10 \mathrm{~m})$ of the landfill contents. The conducted GPR and dipole-dipole resistivity allocated tangibly the locations and depths of the near surface anomalies. Both techniques didn't reveal any possible leakage and/or contamination. Noteworthy, integration among magnetic, GPR, and dipole-dipole resistivity confirmed positively the results of each method. Nevertheless, some anomalies were recognized successfully by one technique and not by the others.
\end{abstract}

\section{Keywords}

Landfill Investigation, Ground Magnetic, GPR, Electric Profiling, Vertical Derivatives, Continuation Filter, Integrated Techniques

\section{Introduction}

Environmental contamination is considered to be one of the main concerns of earth scientists worldwide due to the speed acceleration of industrial development coupled with uncontrolled growth of the urban population which resulted in the increase production of solid/liquid residues. Since the waste materials are usually disposed without the appropriate measures, it imposes a high risk of contamination to the underground water resources. 
Wastes generated from human activities range from simple substance such as food and paper wastes, toxic materials to high level radioactive wastes in the form of nuclear fuel. Hazardous and non-hazardous materials are handled differently in many countries but generally hazardous wastes are thought to be a combination of wastes that affect human health or the environment due to its quantity, concentration, and/or its physical and chemical characteristics when improperly treated, stored, transported or disposed. Certain criteria should be taken in consideration when choosing landfill sites especially the location and size. Other important criteria should be taken in consideration such as: economic, social, environmental, geological, and geomorphologic. Economic and social criteria comprise distance and capacity of the landfill, distance from airports, distance from highways, etc. Environmental criteria include water content, water potential, humidity, ground water flow gradient, permeability, etc. Geological/geomorphologic criteria comprise lithology, depth to the bedrock, structure, etc. In this context, ground magnetic, ground penetrating radar (GPR), and dipole-dipole resistivity profiling were conducted in the study area to characterize the contents of the landfill, moreover, specify any possible leakage and/or contamination (Figure 1). In 2005, reference [1] carried out VLF-EM method, Wenner, and dipole-dipole 2-D resistivity models around a landfill to detect leachate flow and to map its spatial distribution. In 2007, reference [2] used 2D electrical resistance tomography (ERT), electromagnetic measurements using very low frequencies (VLF), electromagnetic conductivity (EM31), seismic refraction measurements (SR), and ambient noise measurements (HVSR) in the largest waste disposal landfill of Crete Island, the Fodele municipal solid waste site (MSW), to determine the geometry of the landfill (depth and spatial extent of electrically conductive anomalies), to define the anisotropy caused by bedrock fabric fractures, and to locate potential zones of electrically conductive contamination. In 2008, reference [3] carried out vertical electrical sounding (VES) and ground penetrating radar (GPR) for the delineation and identification of a contaminant plume in an aquifer in Mexico. In 2010, reference [4] conducted 2D geoelectrical resistivity imaging, soil physic-chemical characterization, and surface water analysis in an unsanitary capped landfill to determine inorganic leachate contamination in the absence of hydrogeological data. In 2011, reference [5] performed an integrated geophysical study involving 2D

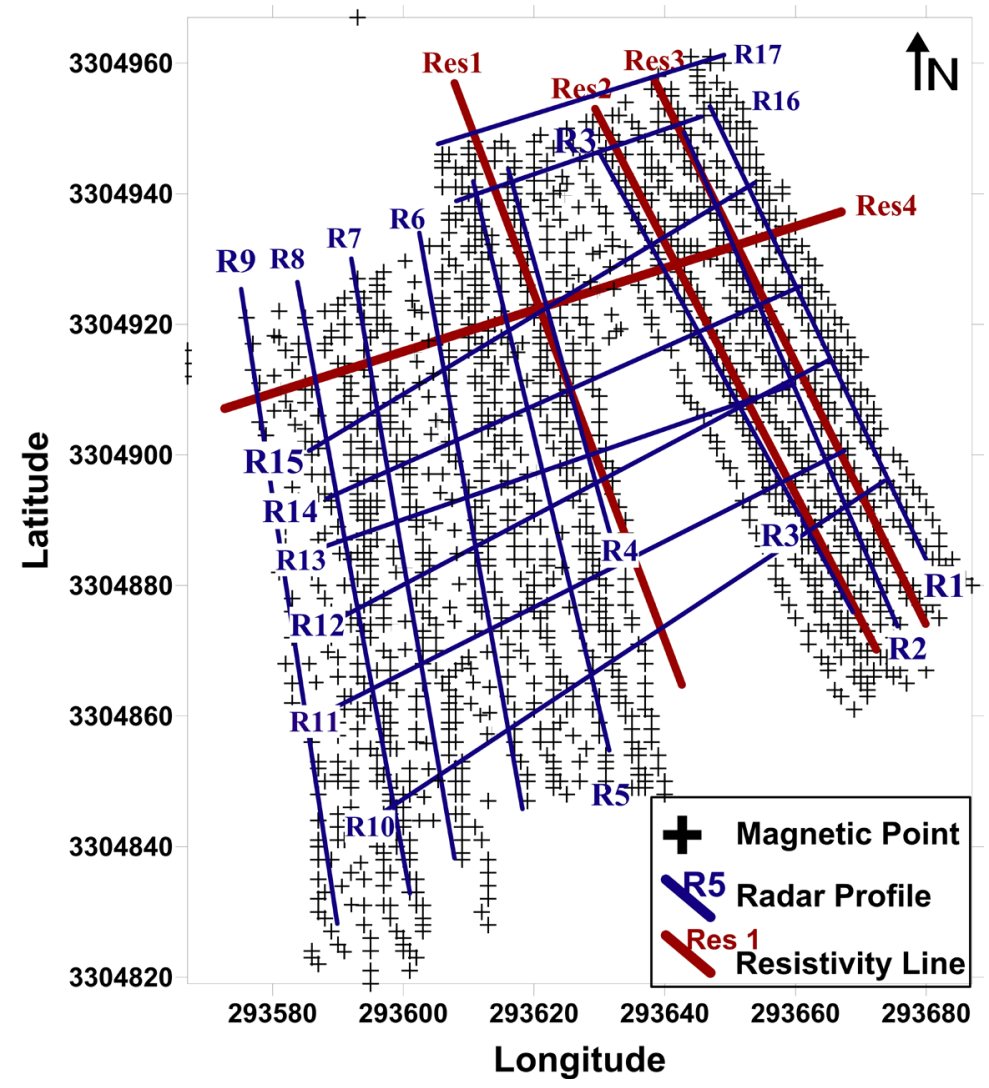

Figure 1. Ground magnetic, ground penetrating radar (GPR) and dipole-dipole geophysical survey carried out in the study area. 
electrical resistivity/induced polarization imaging, very low frequency-EM, and seismic refractionn tomography at Unguwan Dosa municipal solid waste-disposal site in Kaduna metropolis, North Western Nigeria to investigate ground water contamination. In 2015, reference [6] conducted 3D geoelectrical resistivity tomography (ERT) in an old unregulated landfill prior to redevelopment to calculate the geometrical features and general structure of a construction and demolition of a waste layer.

\section{Geological and Structural Setting}

The study area (Figure 2) is mainly composed of early Miocene sediments (Gebel El Khashab formation) which characterized by red mudstone, ironstone, sandstone, tree trunks, and other flora that suggest lower Miocene age. These sediments are characterized by lack of stratifications representing tectonically stable area [7]. Such sediments are closely similar to the facies of Oligocene Qatrani formation, which make the identification of the contact between them difficult. Figure 3 illustrate the generalized subsurface stratigraphic section in the study area.

\section{Methodology}

\subsection{Ground Magnetic Survey}

Very specific criteria should be taken in consideration when magnetic survey is carried out regarding the environmental exploration such as; the accuracy and precision required from the survey, estimated depth, nature and orientation of the target. The interpretation of the magnetic anomalies could be enhanced basically by using various filtering techniques [8]-[13]. In the wave number domain, wavelength and wavelet filters also apply discrete Fourier-transform algorithms [14] [15] which play significant roles in the separation of the shallow and deep magnetic source anomalies [2] [8] [16] [17]. In the study area, the magnetic data were collected using proton

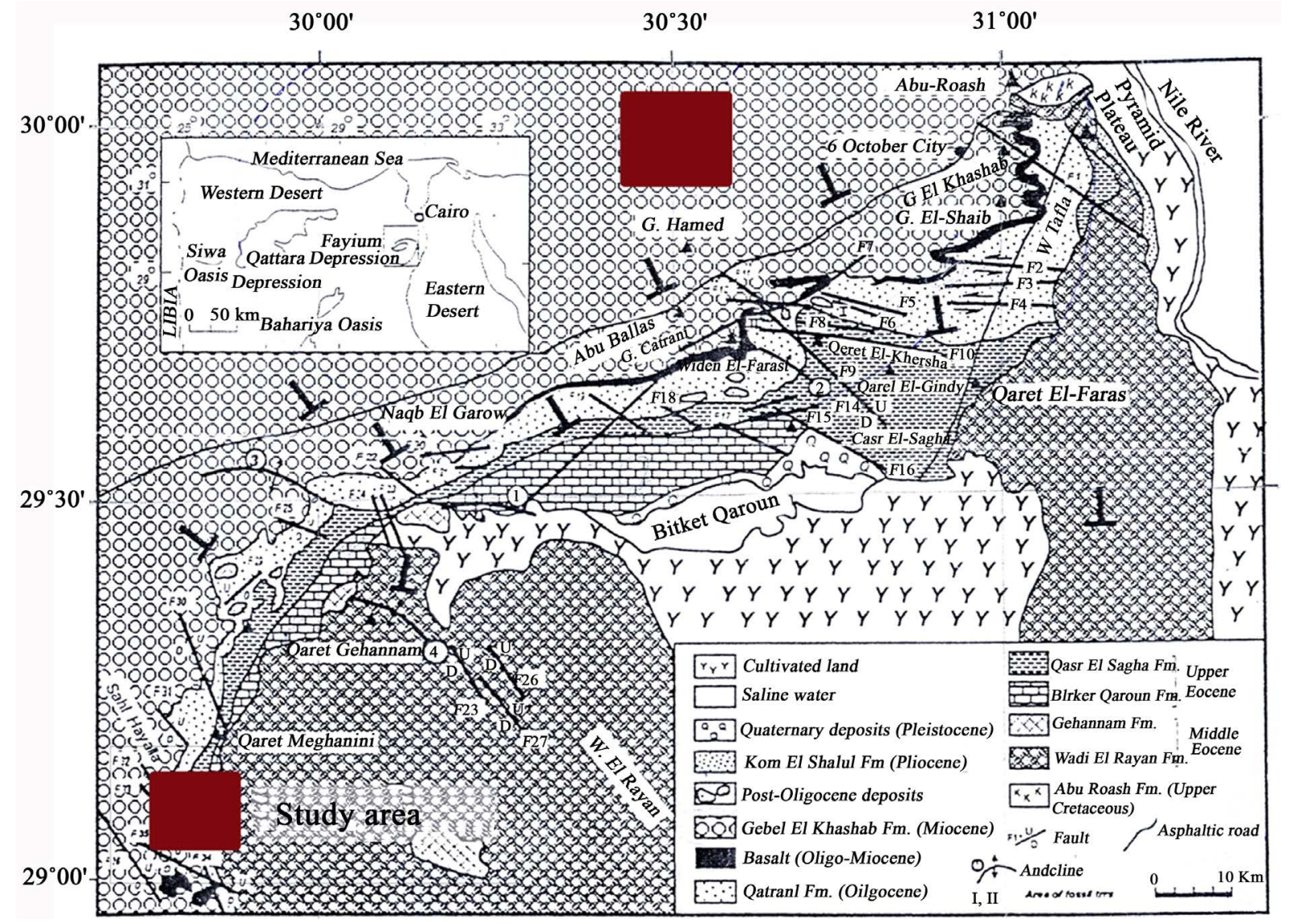

Figure 2. Location map of El-Wahat landfill and geological map of the north Fayium depression. 


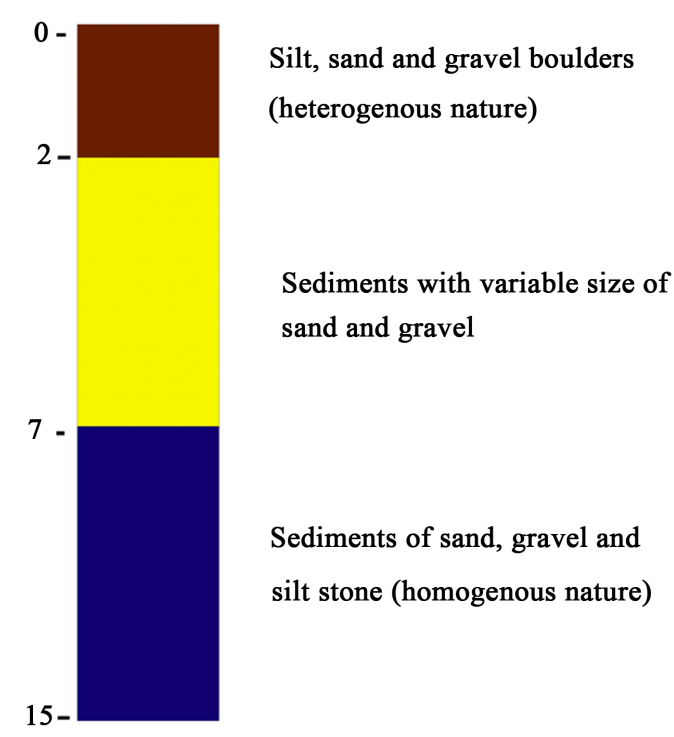

Figure 3. Generalized subsurface stratigraphic section in the study area.

magnetometer. The magnetic grid comprised 31 profiles with line spacing $2 \mathrm{~m}$ and length of $120 \mathrm{~m}$ for each line (Figure 1). The diurnal variation in the total magnetic field was monitored every minute using another proton-magnetometer stationed at a specific location inside the study area. Geosoft Oasis montaj version (6.4) was used to apply various frequency filters and depth estimation.

\subsubsection{Diurnal Correction}

In the magnetic survey, the acquired data contained different elements of noise which should be eliminated. Some correction required to the raw data to remove these noises and enhance contribution caused by the sub-surface magnetic field [18] [19]. The changes of the earth's magnetic field over a daily period is known as diurnal variation which is caused by the change in the direction and strength of current in the ionosphere [19]. In ground based survey, it is important to establish a base station in an area away from magnetic targets or magnetic noise and where the field gradient is relatively flat. In the study area, the diurnal correction was carried out by subtracting the base station magnetic data from observed field magnetic data.

\subsubsection{Reduction to the Pole (RTP)}

The measured magnetic field anomalies are usually shifted from the centers of their magnetic sources due to the inclination and declination of the induced magnetization vector from the magnetic poles [20]. RTP transformation is applied to the total magnetic data to minimize the polarity effects [21] and align the peaks and gradients of magnetic anomalies directly over their sources [22]. RTP calculated in the frequency domain using the following equation [23]:

$$
L(\theta)=\frac{1}{(\sin (I)+i \cos (I) \cos (D-\theta))}
$$

where $\theta$ is the wave number direction, $I$ - the magnetic inclination, and $D$ - the magnetic declination. In the study area, RTP was applied to diurnally corrected data.

\subsubsection{Energy Spectrum (Radially Averaged Power Spectrum)}

Power spectrum is used to calculate the log power spectrum of a channel where wavelength (regardless direction) is plotted against logarithm power of the signal at each wave length [24]-[26]. The energy spectrum of magnetic data exhibits three components, which are; shallow magnetic source component, deep magnetic source component, and noise component. Furthermore, the depth to the magnetic source can be roughly estimated from power spectrum [27]. In the study area, the power spectrum was calculated to estimate the depths of the shallow and deep magnetic sources. 


\subsubsection{Vertical Derivatives}

Derivatives are applied to total magnetic data to enhance the shallowest geologic sources and suppress deeper sources in the data [28]. First and second derivatives emphasize higher gradient, providing sharper resolution and approximate shape outlines of near surface magnetic sources [29]. The first derivative emphasize near surface features, while the second emphasize the plan view boundaries of target zones (especially intra-basement anomaly sources). In the study area, first and second derivatives were calculated from RTP magnetic data.

\subsubsection{Continuation Filtering}

Continuation methods project the observed anomaly field to lower elevations (downward continuation) or to higher elevations (upward continuation) [11]. The most important characteristic of continuation methods is that the character of the geopotential field anomaly is retained as long as the continuation does not extend into the sources. Upward and downward continuations reduce the effects of near surface bodies.

Downward continuation is used to enhance the response from sources at a depth by bringing the plan of measurement closer to the source effectively [11]. Downward usually increase high amplitude and short wavelength noise from shallow sources [13] [30]. In the study area, RTP magnetic data were downward continuated to $0.5,1$, and 1.5 meters.

Upward continuation decreases the effect of higher wave number components associated with more, local near surface anomalies [9]. It projects the observed anomaly field to higher elevations [11]. In the study area, RTP magnetic data was upward continuated to 50, 100, and 150 meters.

\subsubsection{Apparent Susceptibility}

Magnetic susceptibility is the measure of how easily a body can be magnetized [31]. Various magnetic susceptibilities mostly depend on the composition of the lithology. Basement rocks have high magnetic susceptibility due to high magnetic content, while sedimentary rocks have much lower susceptibilities [32]. Susceptibility filters calculate apparent susceptibility of the magnetic sources depending on the assumptions that; there is no remnant magnetization, International Geomagnetic Reference Field (IGRF) of the data has been removed, and all magnetic response is caused by a collection of vertical prisms of infinite depth and strike extent. In the study area, apparent susceptibility was calculated using Geosoft Oasis montaj version (6.4) to depths of 10, 15, and 20 $\mathrm{m}$, with magnetic inclination of $40^{\circ}$, magnetic declination of $2^{\circ}$, and geomagnetic field of 42,000 nT. The result of the apparent susceptibility was presented in CGS electromagnetic unit (EMU).

\subsubsection{Wavelength Filtering}

Wavelength filters are designed to remove either the high wave number noise (due to small, near surface sources) or the longer wavelength component (due to regional anomalies) with low pass and high pass filters, respectively [33]. The significance of this technique depends on the proper choice of the cutoff wavelength used in the filter design [34] [35].

Butterworth low-pass filter known also as maximally flat magnitude filter, is a signal processing filter which is designed to have as flat frequency response as possible in the pass band [33] [36]. The main characteristic of butter-worth filter is that the pass band is maximally flat where no variations occurred in the pass band. In the study area, butter-worth low pass filter with wavelength $\geq 56 \mathrm{~m}$ was designed to enhance and reveal deep seated structures.

Band-pass filter is described as a type of filtering process which refers to the actual portion of affected spectrum [22] [37]. Band-pass filter can be used to pass or reject a range of wave numbers from the data. In the study area, band-pass filter was designed to separate shallow seated source from deep seated source. The filter was designed to pass wavelength between 3 to $20 \mathrm{~m}$.

Cosine roll-off filter is commonly used for high or low pass operations, since it has a smooth shape and does not alter the energy spectrum below the start or after the end of roll-off. In the study area, cosine high and low pass filters were used to separate regional and residual magnetic sources.

Gaussian filter is applied either as low pass or high pass filter to an image along either horizontal or vertical axis. Low Gaussian filter is applied to eliminate high frequency resulting in sharpening features, while high Gaussian filter eliminates low frequency. In the study area, Gaussian high and low-pass filters were used to separate deep and shallow seated components. 


\subsubsection{Analytical Signal}

It is used to calculate the analytical signal of a channel which can be useful in locating the edges of remently magnetized bodies and centering anomalies over their causative bodies in areas of low magnetic latitude [23]. An analytical representation of a real-valued function comprises the original function and its Hilbert transform. Moreover, analytic representation is considered to be generalization of the Phasor concept (which is a complex number representing sinusoidal function). Although Phasor concept is restricted to time-invariant amplitude, phase, and frequency, analytical signal allows for time-variable parameters [38]. If $s(t)$ is a function with Fourier transform $S(f)$, then the function is:

$$
\begin{aligned}
S_{a}(f) & = \begin{cases}2 S(f), & \text { for } f>0 \\
S(f), & \text { for } f=0 \\
0, & \text { for } f<0\end{cases} \\
& =2 u(f) S(f)=S(f)+\operatorname{sgn}(f) S(f)
\end{aligned}
$$

where $u(f)$ is the Heaviside step function and $\operatorname{sgn}(f)$ is the sign function.

The analytic signal of $s(t)$ is the inverse Fourier transform of $S_{a}(f)$, where;

$$
\begin{aligned}
s_{a}(t) & =F^{-1}\left[s_{a}(f)\right]=F^{-1}[S(f)+\operatorname{sgn}(f) \cdot S(f)] \\
& =F^{-1}[S(f)]+F^{-1}[\operatorname{sgn}(f)] * F^{-1}[S(f)] \\
& =s(t)+j\left[\frac{1}{\pi t} * s(t)\right]=s(t)+j \hat{s}(t)
\end{aligned}
$$

where $\hat{s}(t)$ is the Hilbert transform of $s(t)$ and $j$ is the imaginary unit. In the study area, analytic signal was calculated to the magnetic data using Geosoft Oasis montaj version (6.4).

\subsubsection{Depth Estimation by 3D Euler Deconvolution}

In geological and geophysical interpretation, the depth to the source of magnetization is of great importance [39]. The purpose of Euler deconvolution is to produce a map showing locations and corresponding depth estimations of geologic magnetic anomalies in two dimensional grids [40]. This method is based on Euler's homogeneity equation which relate the magnetic field and its gradient components to the location of their sources depending on the degree of homogeneity (SI = Structure Index) [41]. Euler 3D deconvolution given by Reference [41] as;

$$
\left(x-x_{o}\right) \frac{\mathrm{d} T}{\mathrm{~d} x}+\left(y-y_{o}\right) \frac{\mathrm{d} T}{\mathrm{~d} y}+\left(z-z_{o}\right) \frac{\mathrm{d} T}{\mathrm{~d} z}=N(B-T)
$$

where $\left(x_{o}, y_{o}, z_{o}\right)$ is the position of source whose total field $(T)$ is determined at $(x, y, z), B$ is the regional value over the field and $N$ is the structural index.

In the study area, Geosoft Oasis montaj version (6.4) was used to estimate the depth from the total magnetic intensity grid by 3D Euler deconvolution. The depth was estimated using SI $=3$ which corresponded to spheres and barrels, with uncertainty of $\leq 5 \%$.

\subsection{Ground Penetrating Radar (GPR)}

GPR is a high resolution technique of imaging shallow soil and ground structures using electromagnetic (EM) waves in the frequency band of $1-1000 \mathrm{MHZ}$ that are propagated into the ground by a transmitting antenna that is placed on the ground surface [42]. Since it is based on the propagation and reflection of EM waves, it is sensitive to variations of the EM parameters in the subsoil, especially the dielectric constant and the electric conductivity [43]. The transmitting antenna sends out an electromagnetic pulse which is reflected from target bodies and returns to the receiver. At the same time, a receiving antenna detects the waves that are reflected up to the ground surface when the transmitted pulse encounters a subsurface interface across which electromagnetic impedance contrast exists [44]. Reference [3] [45] stated that GPR could be used to identify shallow systems to characterize soils and landfill leaches. The propagation velocity (V) of electromagnetic wave in soil is characterized by dielectric permittivity $(\varepsilon)$, and magnetic permeability $(\mu)$ of the medium; 


$$
V=\frac{1}{\sqrt{\varepsilon \mu}}
$$

In the study area, seventeen GPR profiles were carried out (Figure 1). Data were collected using Mala instrument with shielded antenna of $100 \mathrm{MHz}$. The survey was carried out using grid of $10 \mathrm{by} 10 \mathrm{~m}$. Processing of GPR data were carried out using Reflex software where filters of move start time, subtract-mean (dewow), gain, static correction, background removal, and Kirchhoff migration were applied to the data.

\subsection{Dipole-Dipole Resistivity Survey}

Geoelectric resistivity is one of the most significant variables which reflect the physical properties in a complicated sedimentological environment [46]. Geoelectric resistivity depends mainly on the lithology, water content, porosity, and ionic concentration of the pore fluid [47]. Electrical resistivity imaging (ERI) is considered to be an active geophysical method which measures electric potential differences at specific location while injecting a controlled electrical current at other location [2] [48]. The survey is carried out in the field by applying direct current (DC) between two electrodes implanted in the ground and measure the difference in potential between two additional electrodes that are not carrying current [2]. If the separation between both pairs of electrodes $(a)$ is the same, and the separation between the centers of the dipoles is restricted to $a(n+1)$, the apparent resistivity is given by:

$$
\rho_{a}=\pi a n(n+1)(n+2) V / I
$$

where $I$ is the applied current injected by the potential electrodes, and $V$ is the potential difference measured.

In recent years, one of the new developments is the use of 2D electrical imaging/tomography surveys to map areas with moderately complex geology and investigate landfill characterization [1]-[3] [5] [6]. In the study area, dipole-dipole resistivity survey was conducted to investigate any possible leakage and/or contamination. The survey comprised four lines (three horizontal and one vertical) (Figure 1). The resistivity survey was conducted using Syscal pro instrument.

\section{Results and Discussion}

\subsection{Ground Magnetic Survey}

Since some artificial ore bodies were existed on the surface of the study area, the effect of these bodies were carefully handled during the processing and interpretation of the magnetic data. Figure 4 displayed the contour map of magnetic data after diurnally corrected and reduced to the pole. The contour map revealed the variation of magnetization throughout the study area where maximum magnetization of 43,436 nT characterized the southwestern and northeastern parts of the landfill. Whereas, minimum magnetization of 43,012 nT characterized the northern part of the study area. Radially averaged power spectrum (Figure 5) manifested three linear segments. The first segment (1) corresponded to long wave length (deep-seated magnetic source) while the other two segments (2 and 3) corresponded to short wavelength (shallow-seated magnetic sources).

Shallow-seated magnetic sources; first vertical derivative (Figure 6) illustrated the near surface anomalies with higher resolution while the second derivative was relatively distorted. Downward continuation of magnetic data was carried out for $0.5,1$, and $1.5 \mathrm{~m}$. Figure 7 showed the downward continuation to $0.5 \mathrm{~m}$ which asserted higher wave-number component and visualized anomalies reflecting the individual shallow magnetic sources. Apparent susceptibility of magnetic data was calculated for depths up to 10, 15, and $20 \mathrm{~m}$. Figure 8 showed the apparent susceptibility for depth $15 \mathrm{~m}$. In which the northwestern and northeastern parts of the study area revealed low susceptibility, whereas, the central and southern parts of the area reflected scattered spots and clusters of moderate to high susceptibility. Figure 9 illustrates the band-pass filter (3 - $20 \mathrm{~m})$ where shallow magnetic sources were effectively enhanced and isolated. Nevertheless, a considerable amount of noise and distortion were created due to near surface sources. Figure 10 showed the analytical signal filter where the edges of the near surface anomalies were remarkably identified.

Deep-seated magnetic source; Different wavelength filters such as upward continuation 50, 100, and $150 \mathrm{~m}$, butter worth low-pass, low-pass cosine roll-off, and Gaussian low-pass filters were calculated for the magnetic data in the study area. These filters reflected lower wave-number component and visualized anomalies indicating the major deeper magnetic sources. Figure 11 displayed the upward continuation to $150 \mathrm{~m}$, and Figure 12 

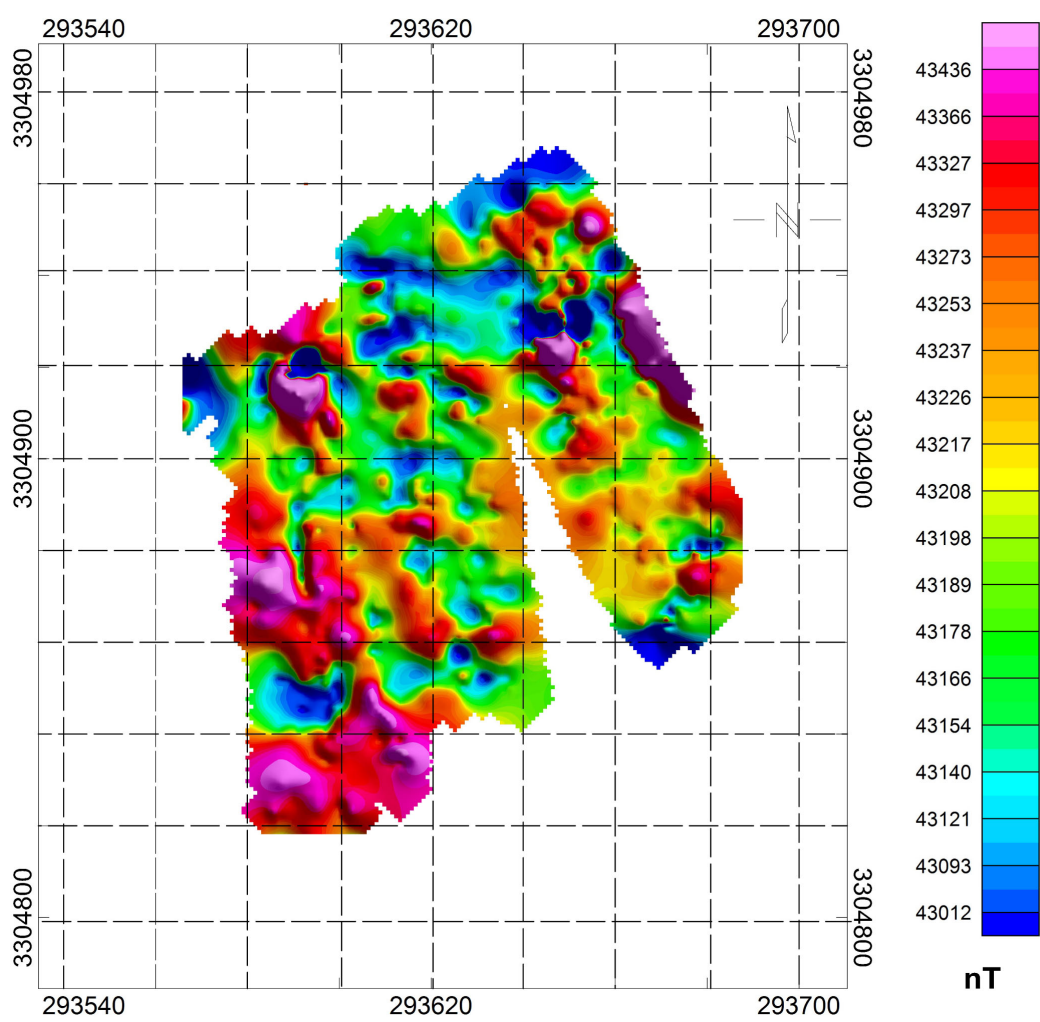

Figure 4. Magnetic contour map diurnally corrected and reduced to the pole.

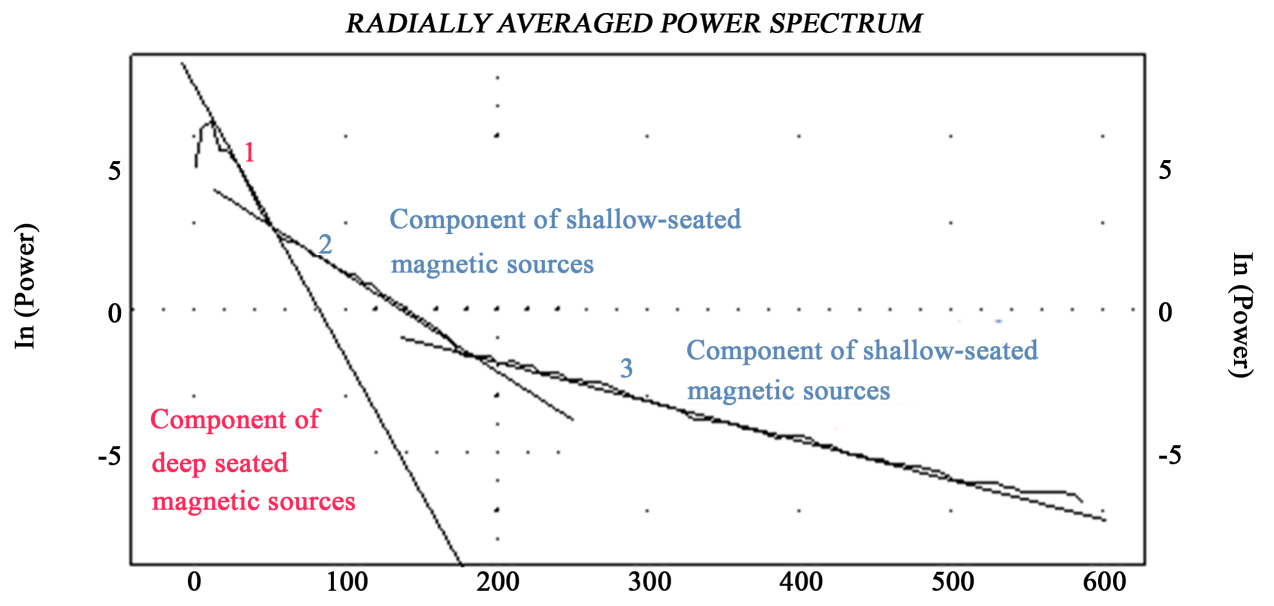

DEPTH ESTIMATE

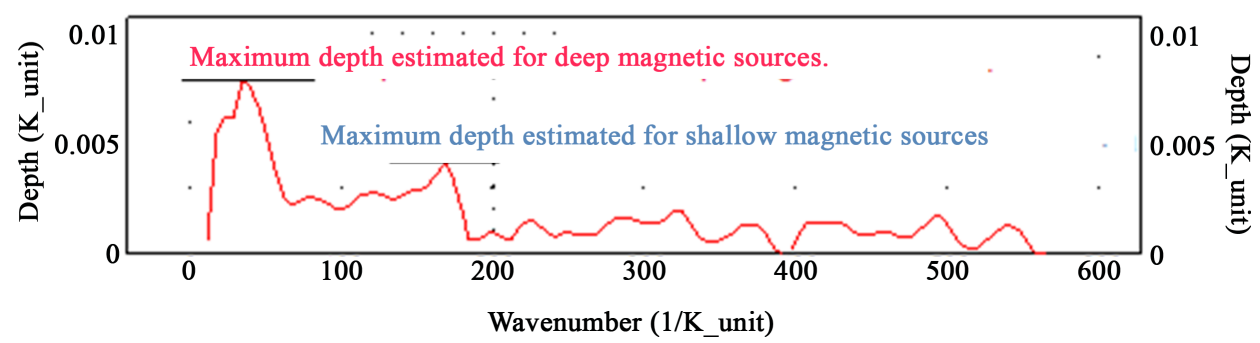

Figure 5. Radially averaged power spectrum and depth estimation of magnetic data. 


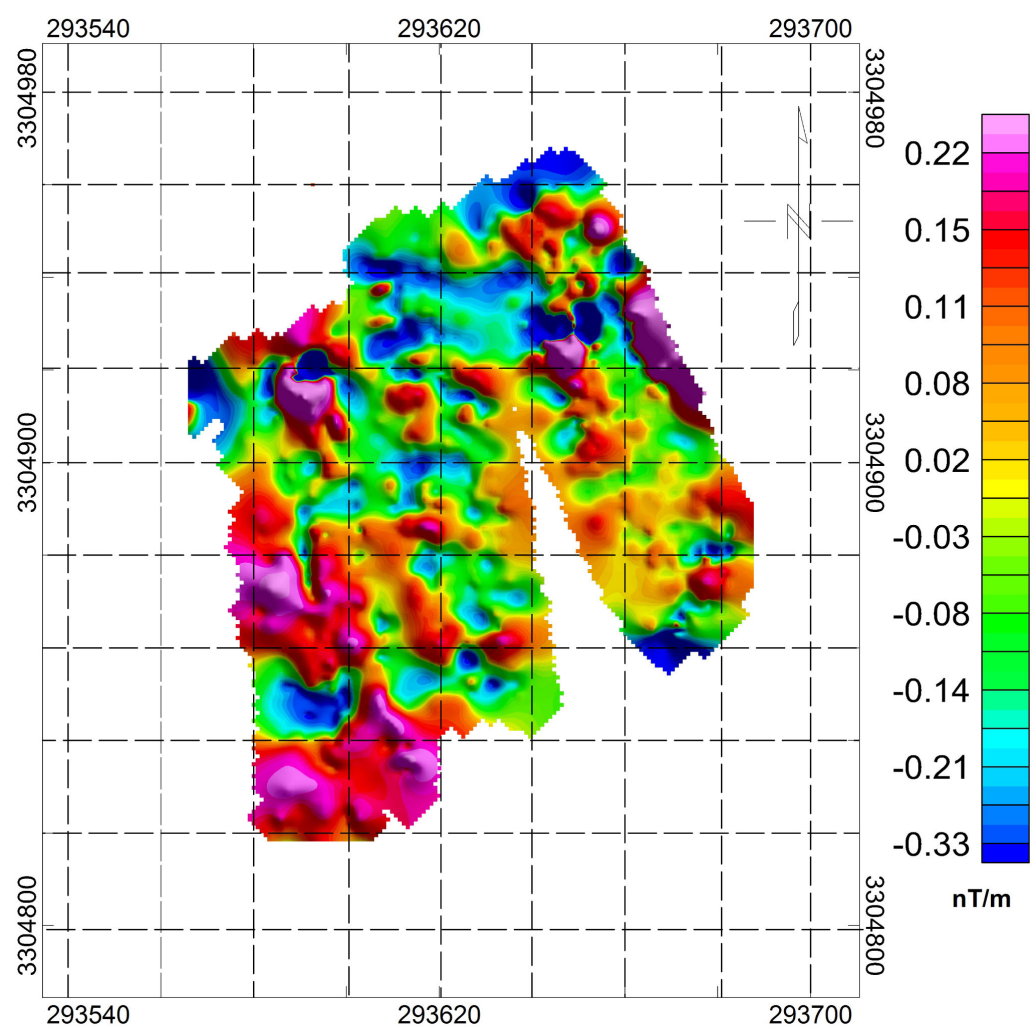

Figure 6. Contour map of the first vertical derivative magnetic data.

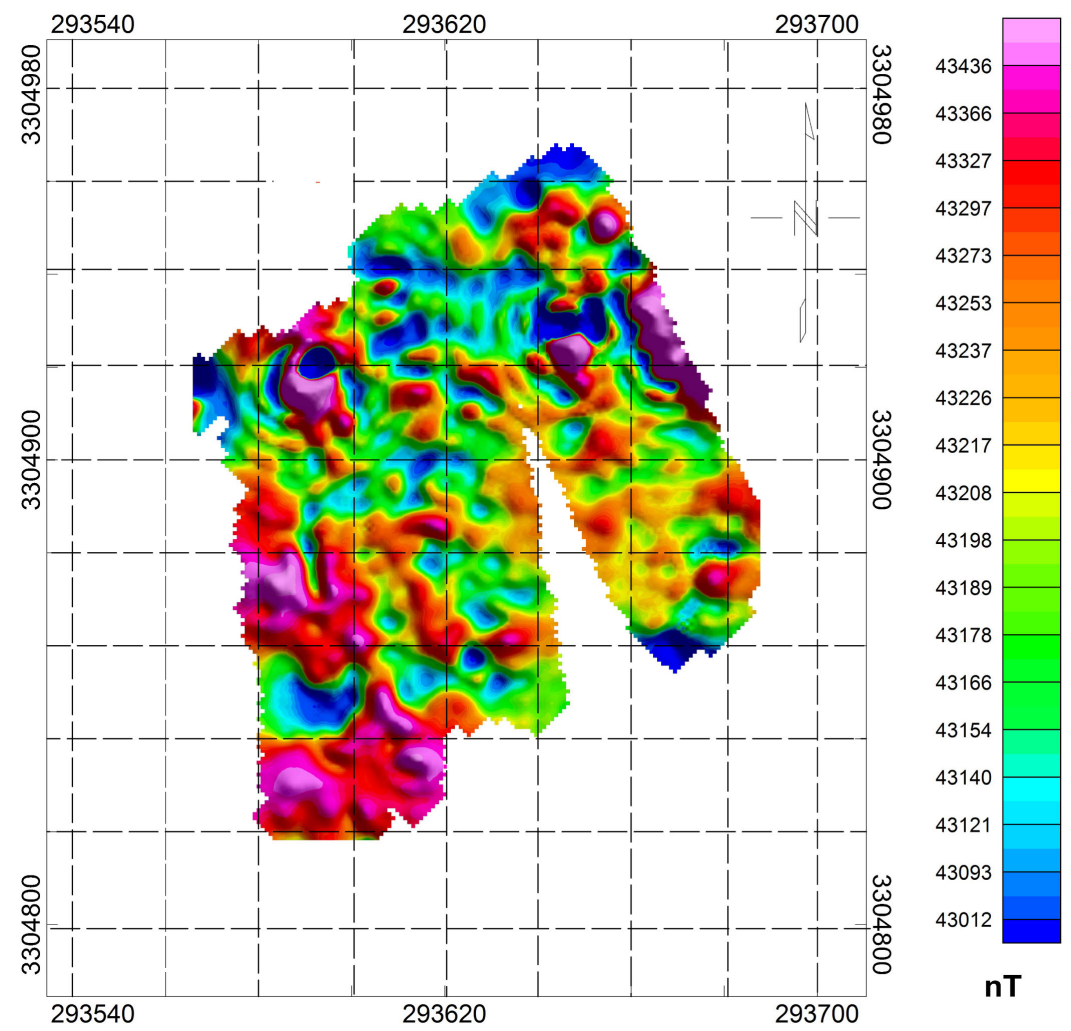

Figure 7. Contour map of the downward continuation to $0.5 \mathrm{~m}$. 

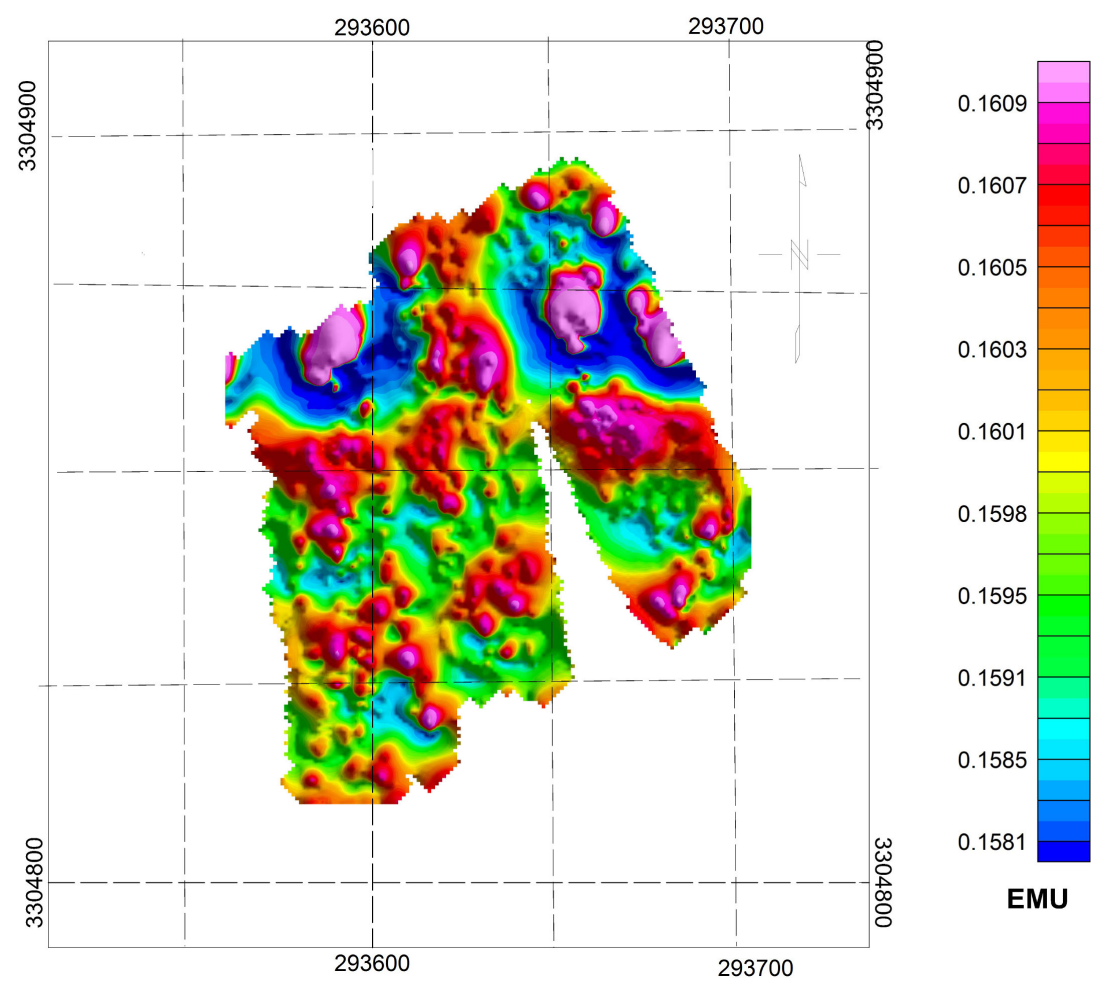

Figure 8. Contour map of apparent magnetic susceptibility up to depth of $15 \mathrm{~m}$.

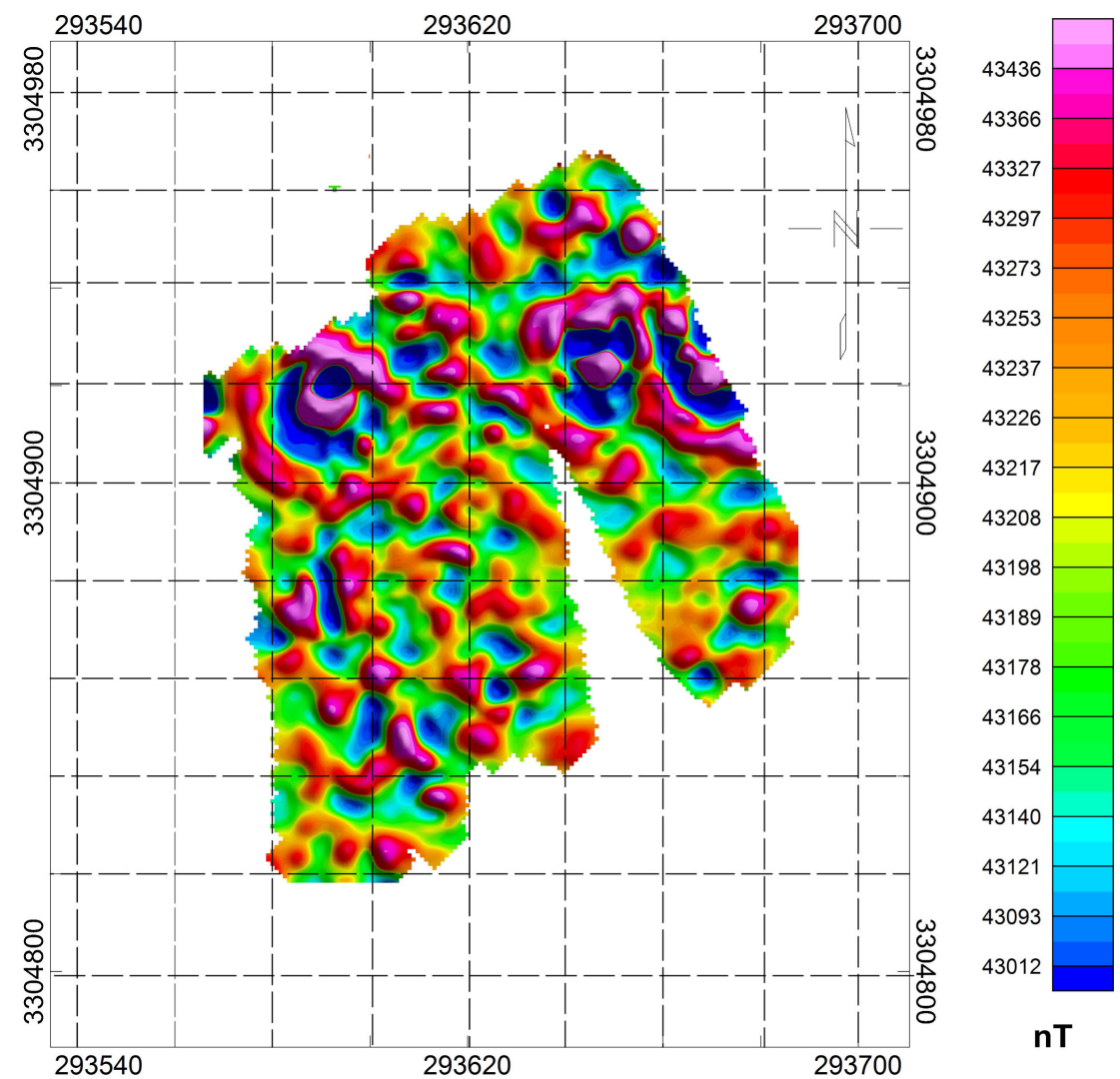

Figure 9. Contour map of the band-pass wave number filters (wavelengths 3 - $20 \mathrm{~m}$ ). 


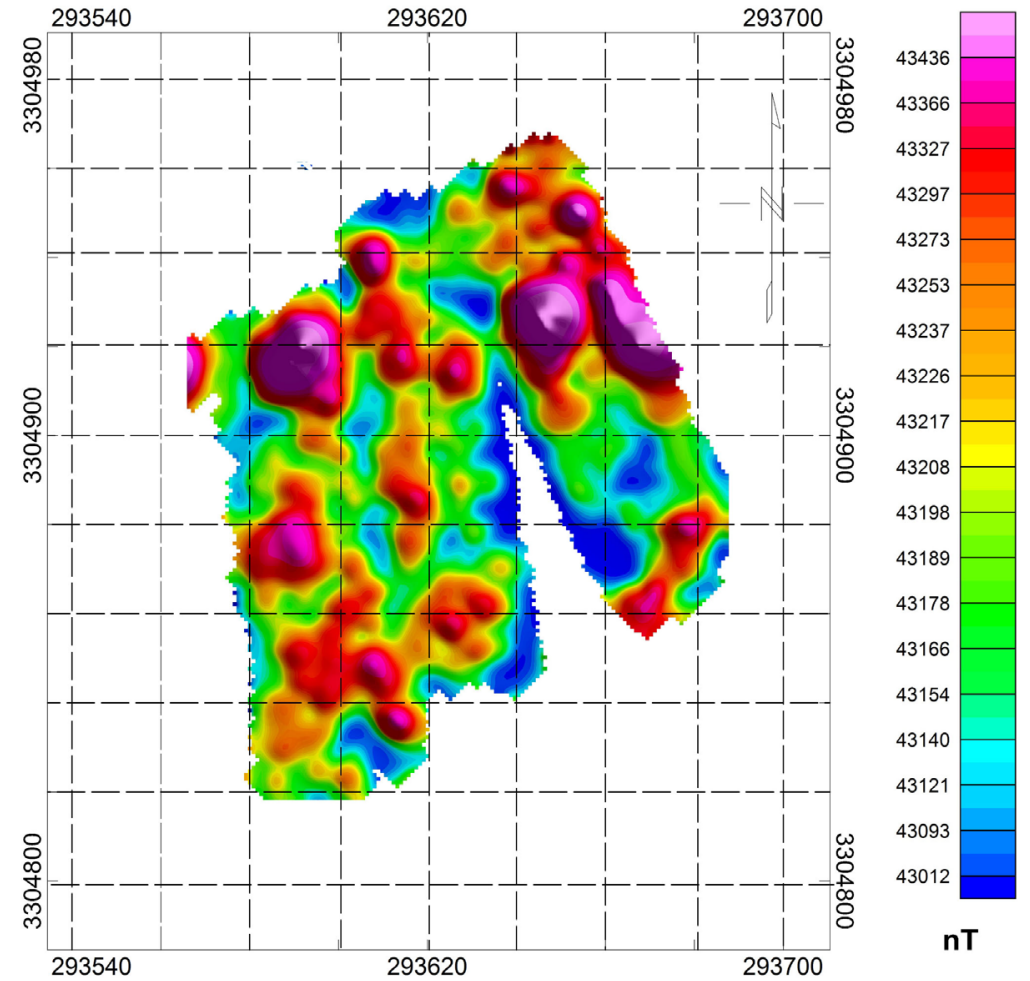

Figure 10. Contour map of analytical signal.

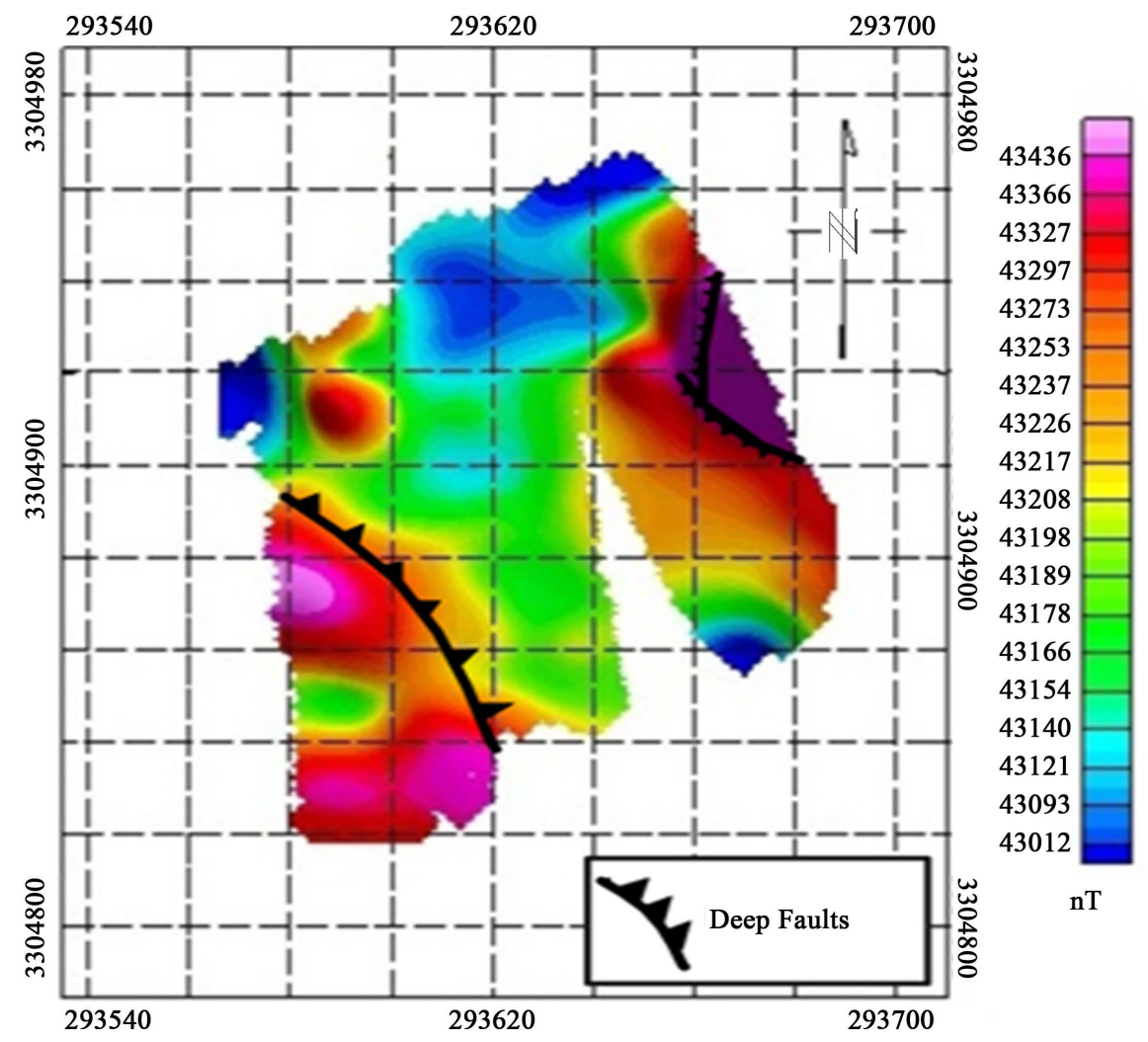

Figure 11. Contour map of the upward continuation to $150 \mathrm{~m}$. 


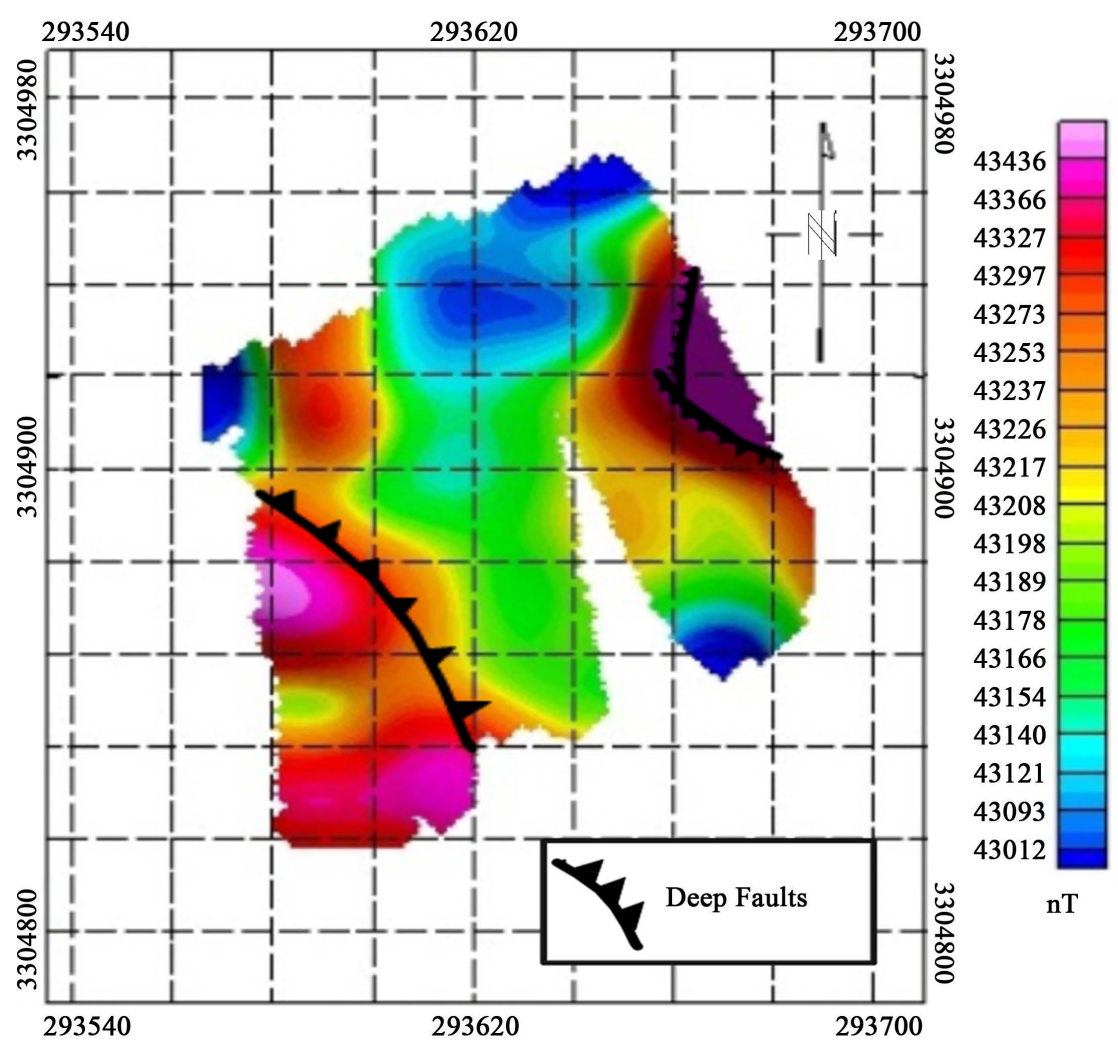

Figure 12. Contour map of the low-pass Gaussian filter.

showed the low-pass Gaussian filter in which major deep faults were determined in the southwestern and northeastern parts of the area. The determined faults were in agreement with the geological subsurface investigations in the area which confirmed the locations and depths of the determined faults.

Figure 13 showed the Euler deconvolution calculated depth (SI = 3) of the shallow sources in the study area. The calculated depths were recognized in good clustering and ranged from 0 to $10 \mathrm{~m}$. At the northwest part of the study area the highest depth of $10 \mathrm{~m}$ was recognized. Whereas, variable depths between 2 to $8 \mathrm{~m}$ were identified in the southwest part and from 2 to $6 \mathrm{~m}$ in the northeast part of the study area. The middle part was characterized by depths ranged from 4 to $6 \mathrm{~m}$.

\subsection{Ground Penetrating Radar}

The interpretation of the seventeen GPR cross sections (Figure 1) revealed anomalies reflecting the dielectric contrast of the source bodies in hyperbolic shapes on the sections (Figure 14). The length of the GPR crosssection ranged from 60 to $80 \mathrm{~m}$ with depths from 0 to $10 \mathrm{~m}$.

Figure 14 showed samples (R1, R5, and R17) of the radar cross sections carried out in the study area. Radar cross section R1 revealed twelve anomalies annotated by symbols from G1 to G9 and with alphabetical letters "L”, "P”, and “R” with depth ranged from 2 to $7 \mathrm{~m}$. Radar cross section R5 revealed seven anomalies. Whereas, no declared anomalies were recognized in R17. Noteworthy, R17 was conducted out of the study area to recognize and/or allocate any possible buried wastes out of the border of the study area where the measured data didn't allocate any.

The lithology declared in the radar cross-sections confirmed with the lithology detected from the geological investigation in the area (Figure 3). However, in the radar cross-sections it was hard to sharply separate between different layers due to their very similar lithology composition.

\subsection{Dipole-Dipole Resistivity Survey}

The interpreted dipole-dipole resistivity sections represented the variation of the resistivity throughout the study 

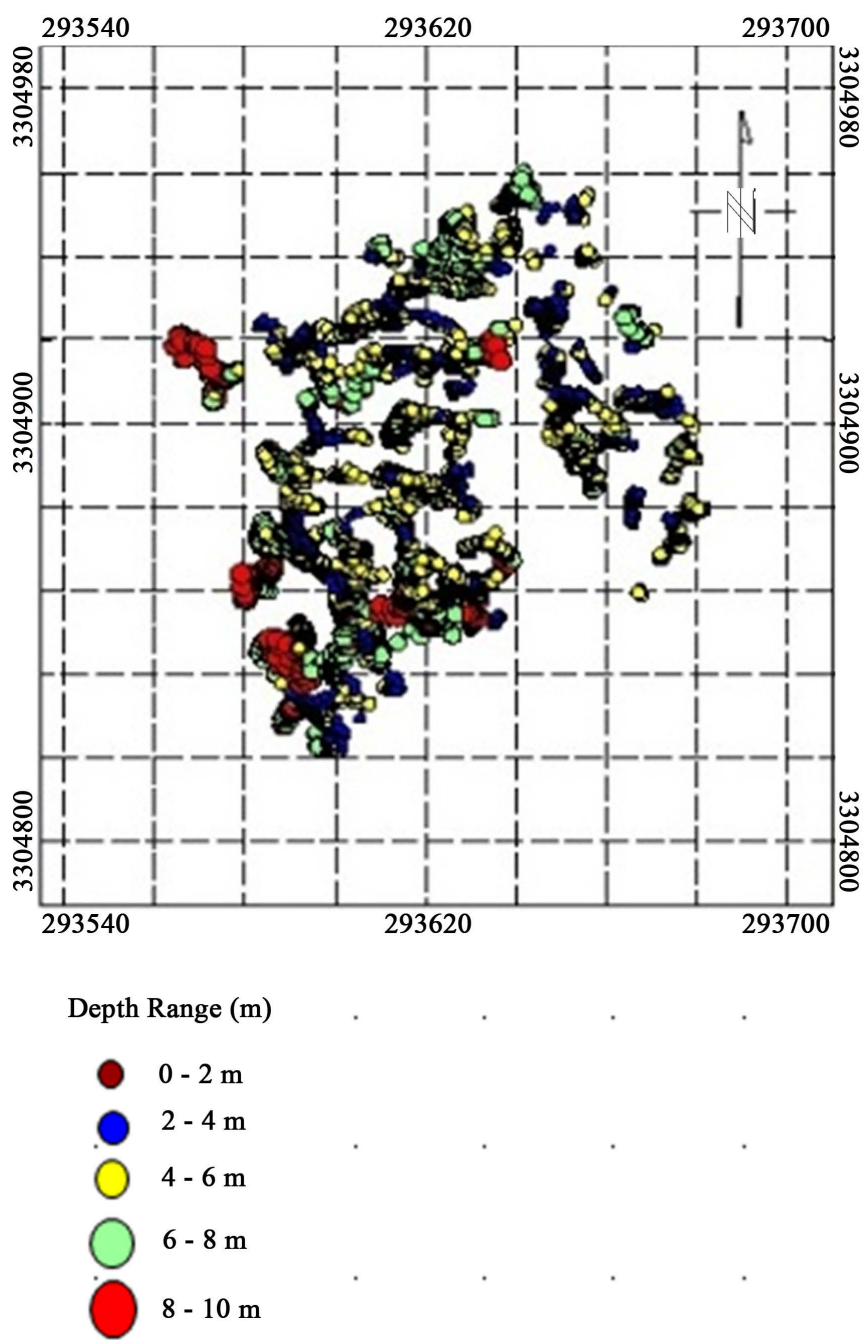

Figure 13. 3D Euler deconvolution applied to the total magnetic intensity (SI $=3)$, uncertainty $\leq 5 \%$.

area (Figure 1). Low resistivity values were recognized at the southern part of the sections and increased gradually towards the north. The geo-electric resistivity cross sections extended $180 \mathrm{~m}$ in length with depths ranged from 2 to $8 \mathrm{~m}$. In Res1 five declared anomalies were recognized V, Res2, U, Res1, and Q from east to west, respectively, with anomalies ranged from 210 to $259 \Omega \cdot \mathrm{m}$ (Figure 15). In Res2 eight pronounced anomalies were recognized S, F, M, Res3, A, Res4, T, and N from west to east, respectively, with anomalies ranged from 157 to $225 \Omega \cdot \mathrm{m}$ (Figure 15). In Res3 seven declared anomalies were recognized Z, L, T, Res6, F, Res5, and S from east to west, respectively, with anomalies ranged from 165 to $215 \Omega \cdot \mathrm{m}$ (Figure 15). In Res4 four proclaimed anomalies were recognized P, F, W, and Res7 at northwestern of the study area, with anomalies ranged from 245 to $293 \Omega \cdot \mathrm{m}$ (Figure 15).

\subsection{Integrated Interpretation}

After individual interpretation was carried out for each survey independently (magnetic, GPR, and resistivity), the results of all surveys were interpreted in an integrated manner. Figure 16 represented the contour map of the interpreted magnetic data overlaid by the GPR lines carried out in the study area. GPR lines were represented by symbols from R1 to R17. Furthermore, Figure 17 displayed the contour map of the interpreted magnetic data overlaid by the resistivity lines conducted in the study area. Resistivity lines were referred by Res1 to Res4. Figure 18 indicated the magnetic anomalies of the landfill contents. These anomalies were referred by the alphabetic letters from A to I'. 

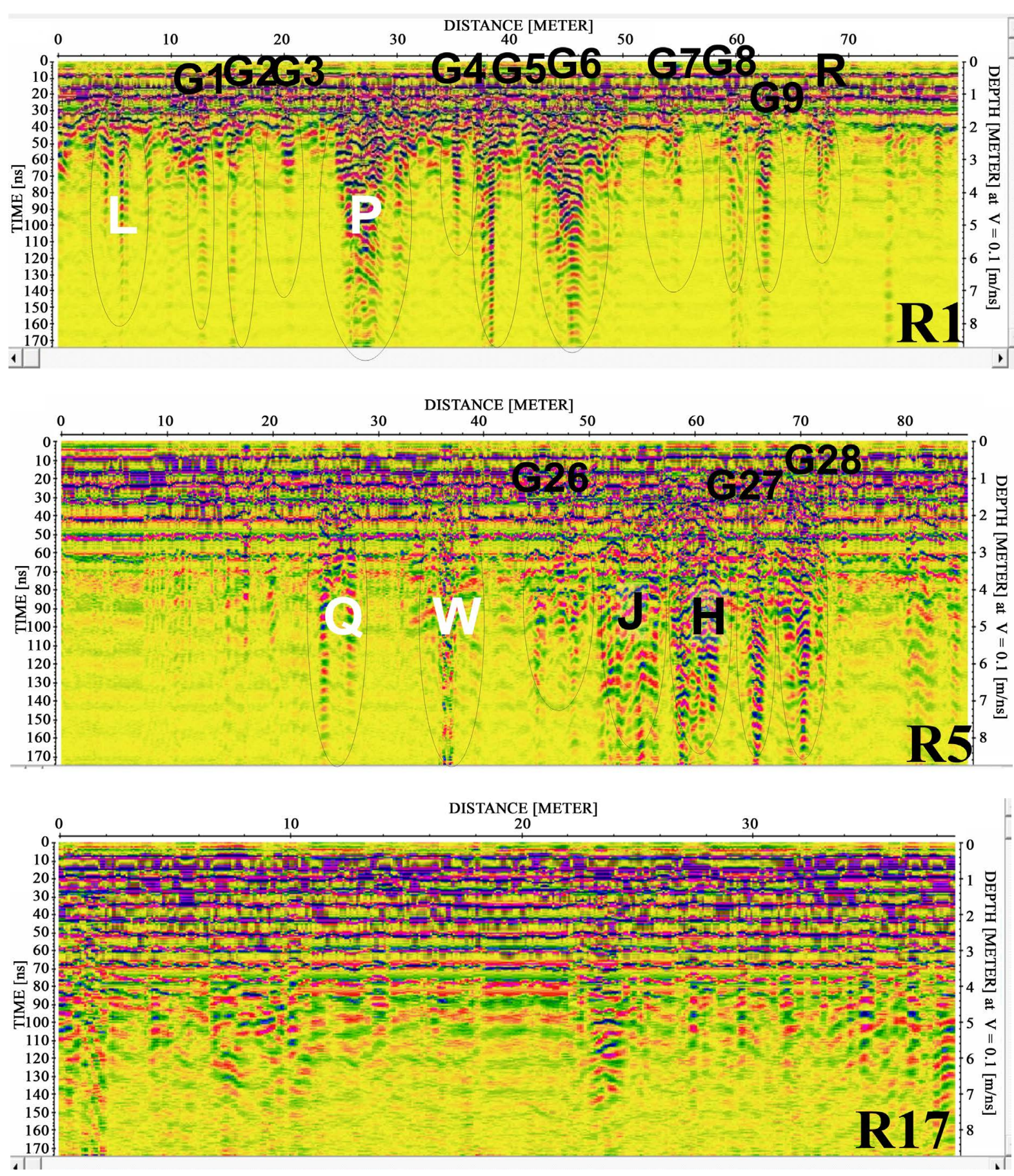

Figure 14. Sample of the radar cross section carried out in the study area.

From integrated interpretation of the data (magnetic, GPR, and dipole-dipole resistivity), it turns out that the interpretation can be classified into three different categories. First category; common anomalies resulted from the interpretation of the three methods (magnetic, GPR, and dipole-dipole resistivity) such as the magnetic anomaly P (Figure 18) which corresponded to P anomaly in GPR cross section represented in R1 (Figure 14) and resistivity anomaly $\mathrm{P}$ represented in resistivity section Res 4 (Figure 15). Similarly, other common anomalies among magnetic, GPR, and dipole-dipole resistivity such as W, L, and Q could be recognized in Figure 14, Figure 15, and Figure 18. Second category: common anomalies pronounced from two methods only, magnetic and resistivity and/or magnetic and GPR. For instance; magnetic anomaly F was declared in 


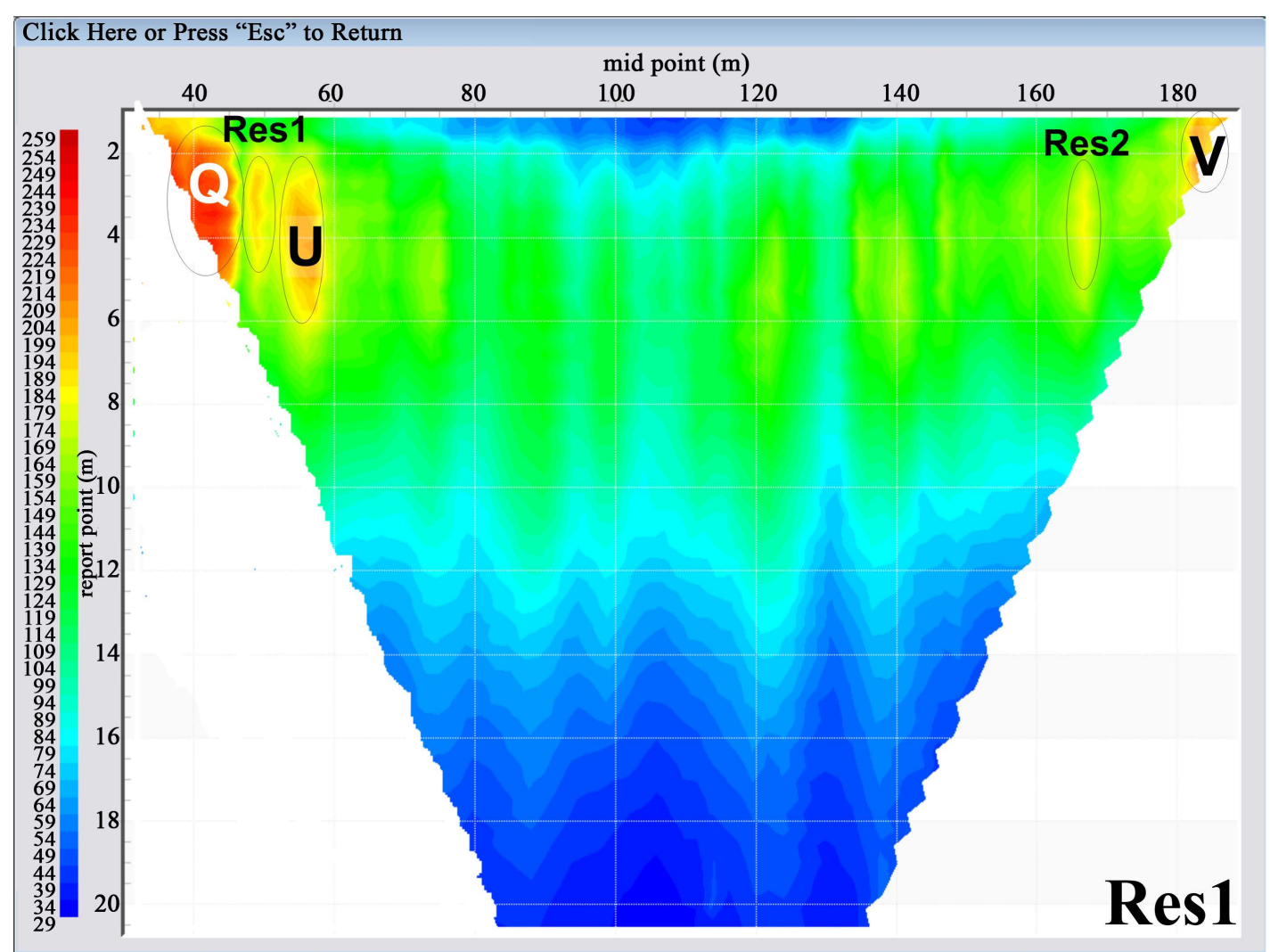

(a)

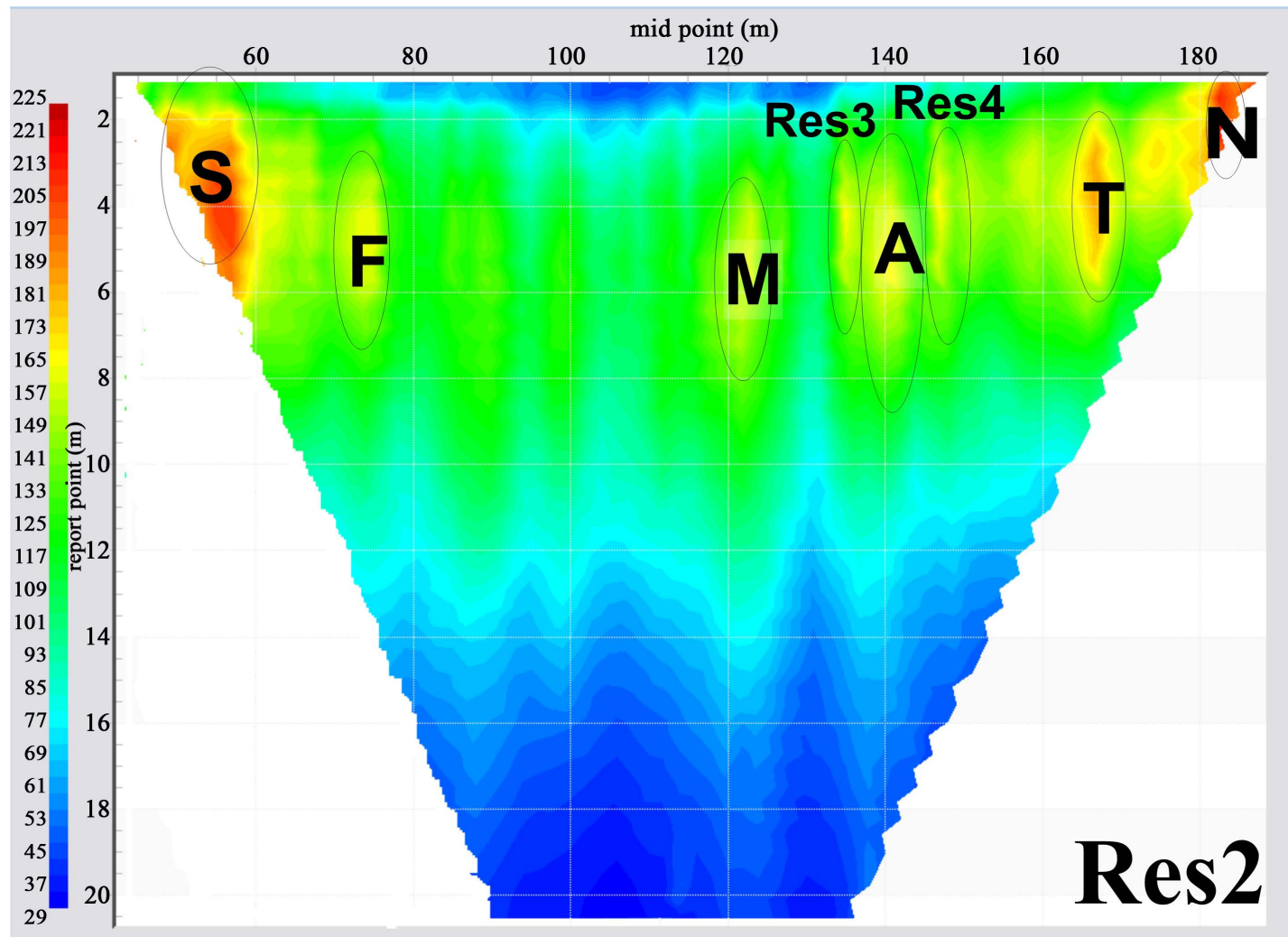

(b) 


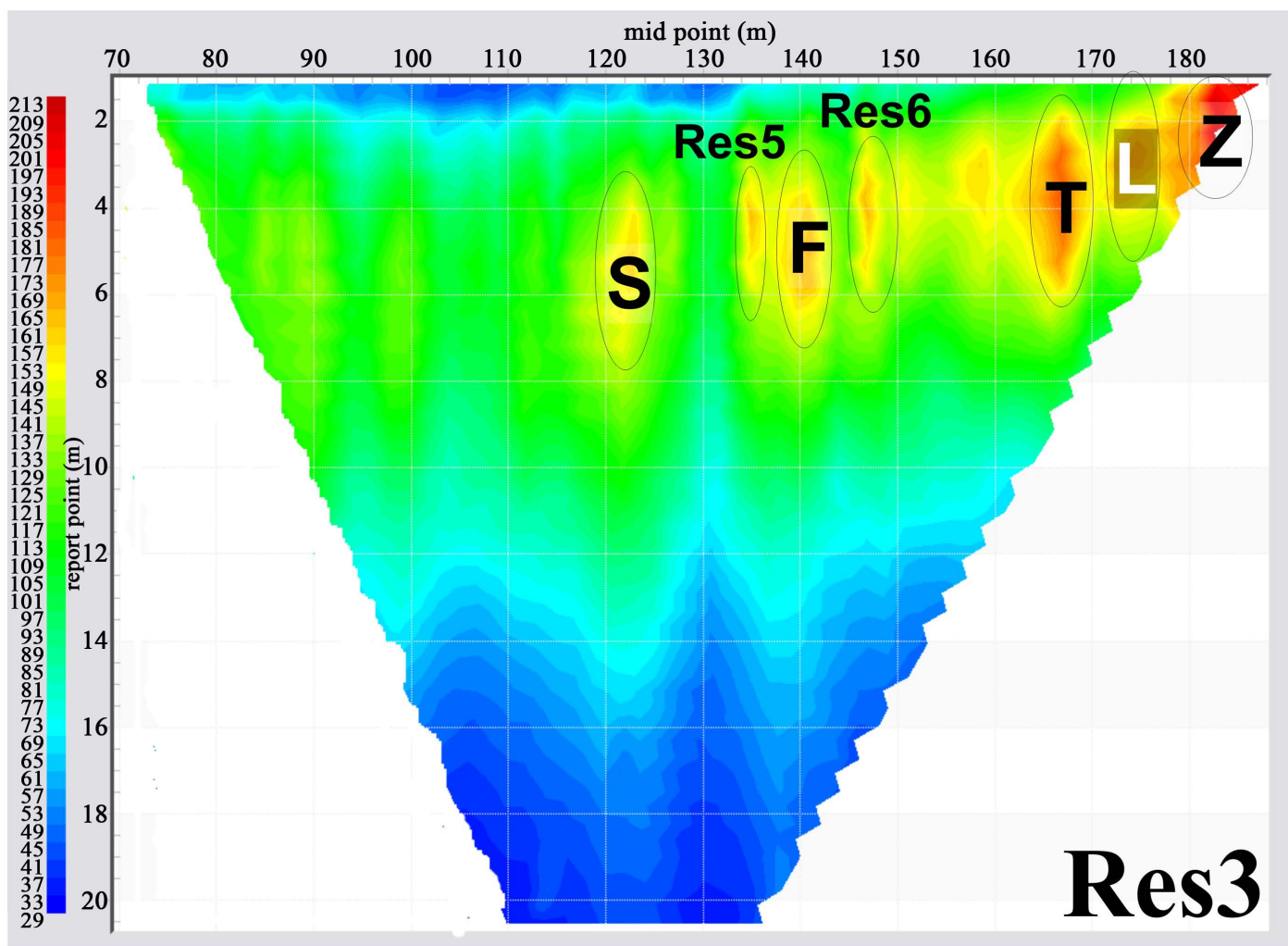

(c)

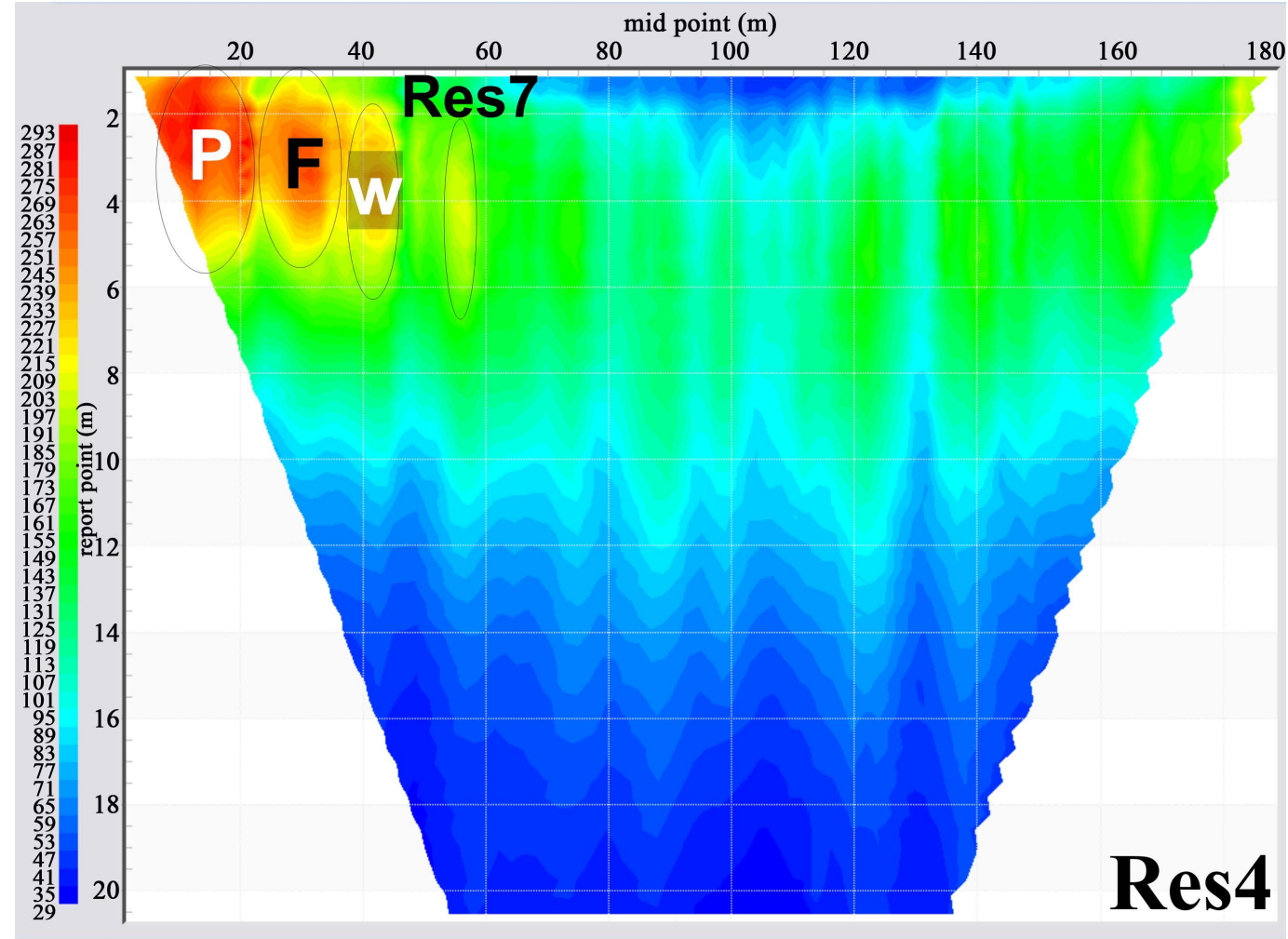

(d)

Figure 15. Dipole-dipole resistivity data carried out in the study area (Res1, 2, 3, and 4). 


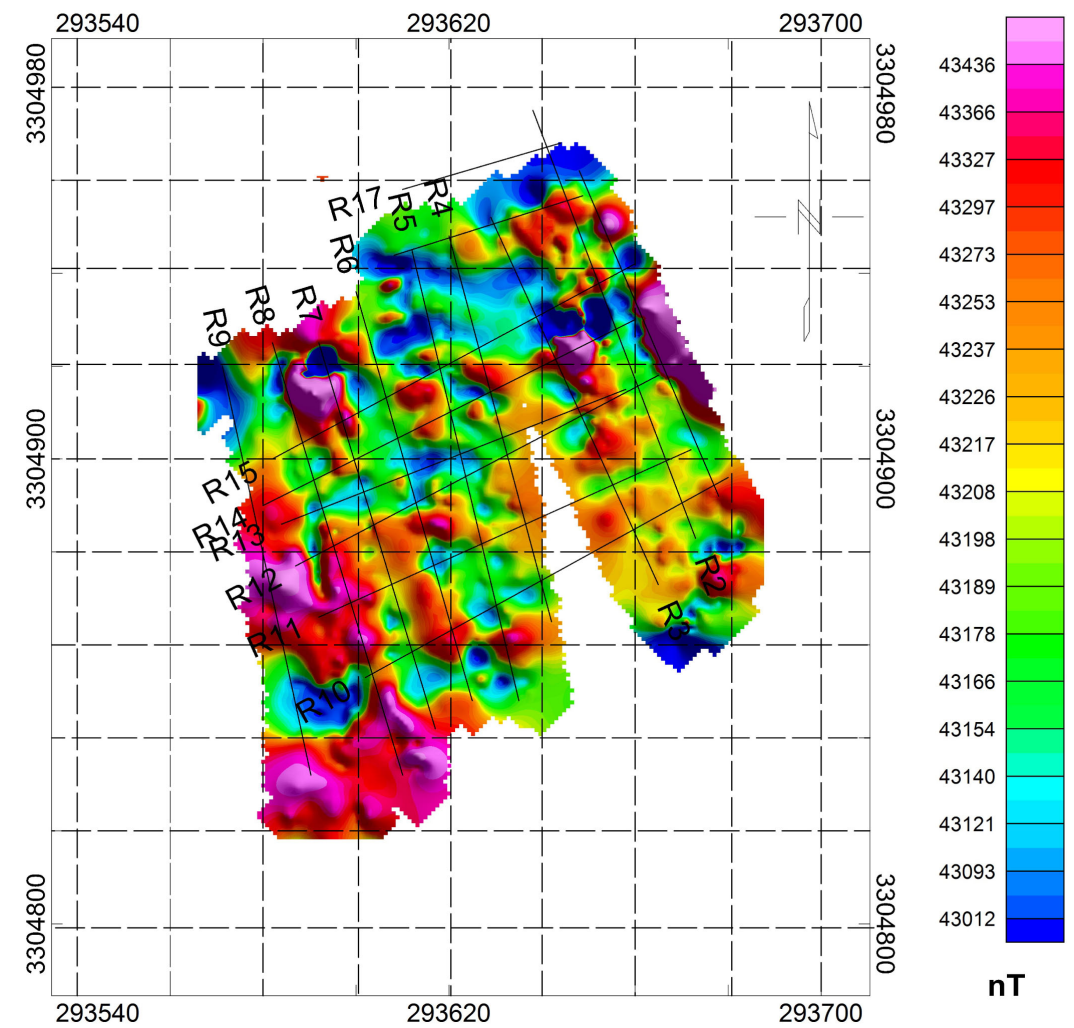

Figure 16. Magnetic contour map of the study area overlaid by the locations of the GPR lines.
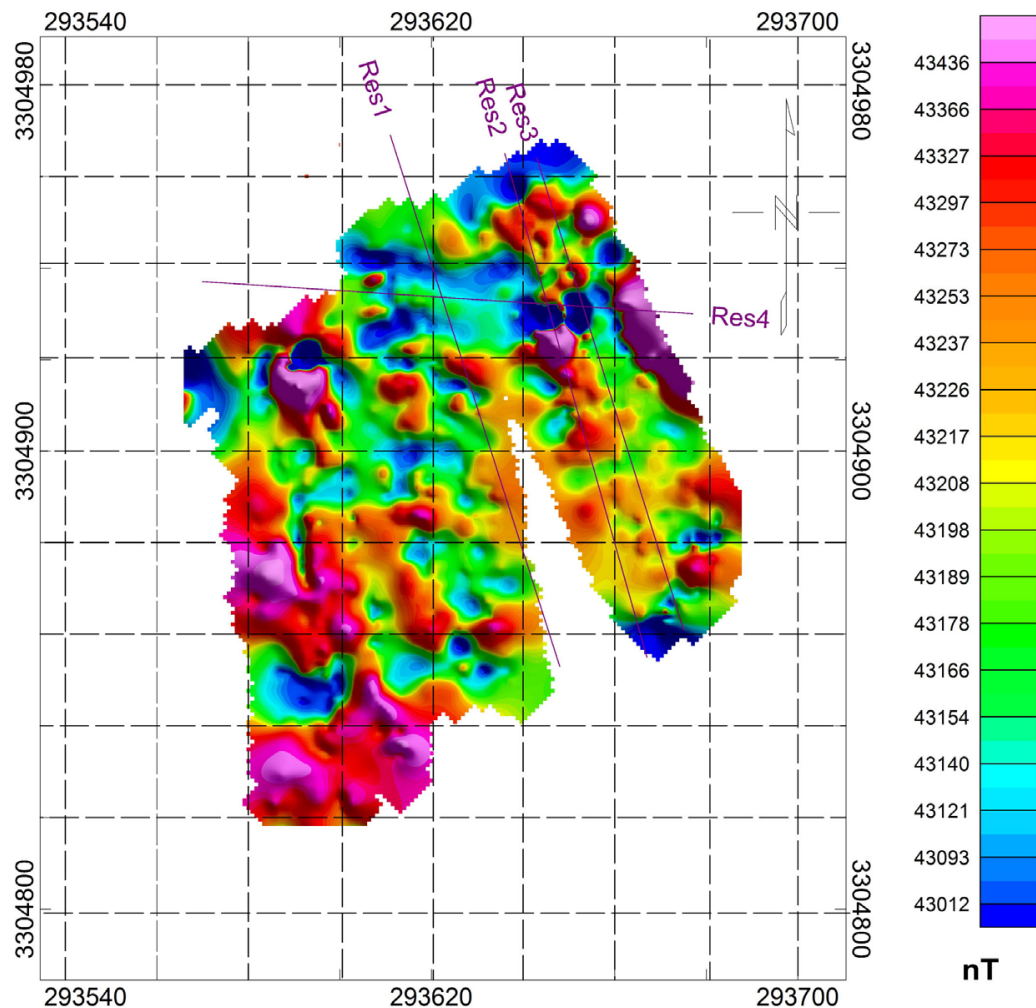

Figure 17. Magnetic contour map of the study area overlaid by the location of the four dipole-dipole resistivity lines. 


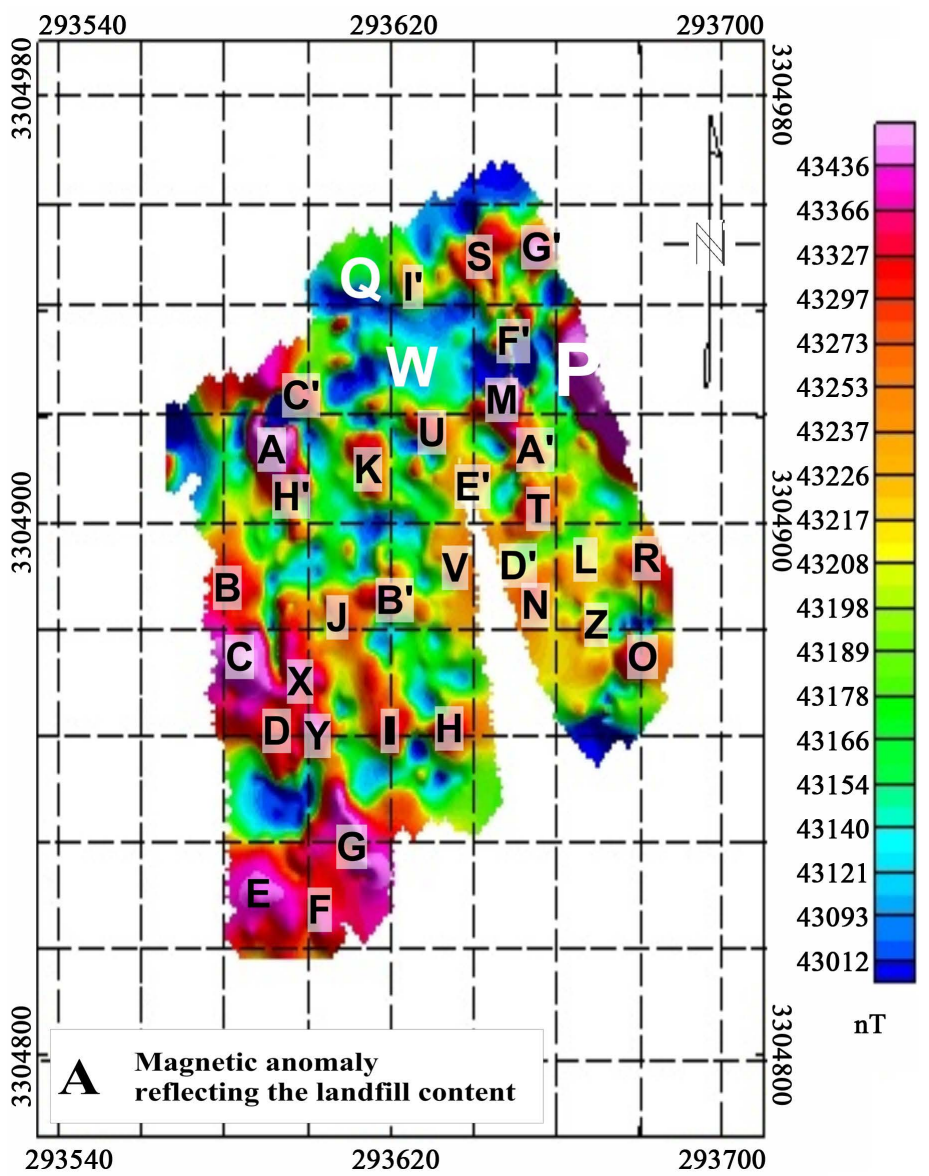

Figure 18. Map indicating the anomalies locations of the landfill contents deduced from magnetic.

magnetic (Figure 18) which corresponded to $\mathrm{F}$ in the dipole-dipole resistivity which was represented in resistivity section Res 4 (Figure 15). Whereas, anomaly J was displayed in GPR section R5 (Figure 14) and magnetic survey as well (Figure 18). Third category: non-common anomalies which declared only from one method. For instance; some anomalies were declared in magnetic only such as B, C, D, E, I, K, O, X, Y, A', B', C', D', E', F', G', H', and I' (Figure 18). Similarly, anomalies declared only in GPR such as G1, G2, G3, G4, G5, G6, G7, G8, G26, G27, and G28 (Figure 14). Similarly, anomalies declared only in dipole-dipole resistivity such as Res1, Res2, Res3, Res4, Res5, Res6, and Res7.

\section{Conclusions}

In this work, ground magnetic, GPR, and dipole-dipole resistivity profiling were successfully interpreted in an integrated manner to investigate landfill contents and/or identify any possible leakage and/or contamination in the study area. Ground magnetic survey comprised 31 profiles with line spacing $2 \mathrm{~m}$ and length of $120 \mathrm{~m}$ for each (Figure 1). Whereas, GPR survey comprised 17 profiles with lengths ranged from 60 to 80 m (Figure 1). Dipole-dipole resistivity survey comprised 4 profiles with lengths of $180 \mathrm{~m}$ (Figure 1).

The magnetic data were diurnally corrected and reduced to the pole (Figure 4). Radially averaged power spectrum remarkably estimated the depth of the shallow and deep magnetic sources (Figure 5) which significantly contributed in the designing of the conducted filters. Near surface contents of the landfill were significantly indicated by pronounced anomalies in the vertical derivative (Figure 6), downward continuation to $0.5 \mathrm{~m}$ (Figure 7), apparent susceptibility magnetic to $15 \mathrm{~m}$ (Figure 8), band-pass filter (3 - $20 \mathrm{~m}$ ) (Figure 9), and the analytical signal filter (Figure 10). Noteworthy, the analytical signal was the most powerful and significant technique in isolating the contents of the landfill. Whereas, deep structure were remarkably indicated by declared anomalies in upward continuation up to $150 \mathrm{~m}$ (Figure 11) and low-pass Gaussian filter (Figure 12). Eu- 
ler deconvolution (SI = 3) successfully calculated the depth of the shallow sources in the study area (Figure 13). The calculated depths were recognized in good clustering and ranged from 0 to $10 \mathrm{~m}$.

Interpretation of the GPR cross sections revealed clearly the subsurface down to depth of $10 \mathrm{~m}$ (Figure 14). The GPR hyperbolic anomalies were declared clearly reflecting the dielectric contrast of the source bodies. Nevertheless, the lithology discrimination in the GPR cross-sections was not sharply separate due to the very similarly in the composition.

Interpretation of the dipole-dipole resistivity successfully imaged the subsurface down to depth of $8 \mathrm{~m}$ (Figure 15). Resistivity values in the cross section ranged from 29 to $293 \Omega \cdot \mathrm{m}$. Low resistivity values were recognized at the southern part of the sections and increased gradually towards the northern parts. The recognized anomalies of the landfill contents were ranged from 157 to $293 \Omega \cdot \mathrm{m}$.

Integrated interpretation of the three methods magnetic, GPR, and dipole-dipole resistivity classified the recognized anomalies into three different categories. First category: common anomalies resulted from the interpretation of the three methods such as the magnetic anomaly P (Figure 18) which corresponded to P anomaly in GPR cross section represented in R1 (Figure 14) and resistivity anomaly P represented in resistivity section Res 4 (Figure 15). Similarly, other common anomalies among magnetic, GPR, and dipole-dipole resistivity such as W, L, and Q could be recognized in Figure 14, Figure 15, and Figure 18. Second category: common anomalies pronounced from two methods only, magnetic and resistivity and/or magnetic and GPR. For instance; magnetic anomaly $\mathrm{F}$ was declared in magnetic (Figure 18) which corresponded to F in the dipole-dipole resistivity which was represented in resistivity section Res 4 (Figure 15). Whereas, anomaly J was displayed in GPR section R5 (Figure 14) and magnetic survey as well (Figure 18). Third category: non-common anomalies which declared only from one method. For instance; some anomalies were declared in magnetic only such as B, C, D, E, I, K, O, $\mathrm{X}, \mathrm{Y}, \mathrm{A}^{\prime}, \mathrm{B}^{\prime}, \mathrm{C}^{\prime}, \mathrm{D}^{\prime}, \mathrm{E}^{\prime}, \mathrm{F}^{\prime}, \mathrm{G}^{\prime}, \mathrm{H}^{\prime}$, and I' (Figure 18). Similarly, anomalies declared only in GPR such as G1, G2, G3, G4, G5, G6, G7, G8, G26, G27, and G28 (Figure 14). Similarly, anomalies declared only in dipole-dipole resistivity such as Res1, Res2, Res3, Res4, Res5, Res6, and Res7. Noteworthy, the interpretation of the applied techniques in an integrated manner remarkably allocated the different types of contents of the landfill and estimated their corresponding depths. Furthermore, the applied techniques confirmed no leakage and/or contamination in the surrounding environment.

\section{References}

[1] Monteiro, F.A., António Mateus, S., Figueiras, J. and Gonçalves, M.A. (2006) Mapping Groundwater Contamination Around a Landfill Facility Using the VLF-EM Method: A Case Study. Journal of Applied Geophysics, 60, 115-125. http://dx.doi.org/10.1016/j.jappgeo.2006.01.002

[2] Soupios, P., Papadopoulos, N., Papadopoulos, I., Kouli, M., Vallianatos, F., Sarris, A. and Manios, T. (2007) Application of Integrated Methods in Mapping Waste Disposal Areas. Environmental Geology, 53, 522-531. http://dx.doi.org/10.1007/s00254-007-0681-2

[3] Reyes-López, J.A., Ramírez-Hernández, J., Lázaro-Mancilla, O., Carreón-Diazconti, C. and Martín-Loeches Garrido, M. (2008) Assessment of Groundwater Contamination by Landfill Leachate: A Case in México. Waste Management, 28, 33-39. http://dx.doi.org/10.1016/j.wasman.2008.03.024

[4] Rahim Bahaa-Eldin, E.A., Yusoff, I., Abdul Rahim, S., Wan Zuhairi, W.Y. and Abdul Ghani, M.R. (2010) Tracing Subsurface Migration of Contaminants from an Abandoned Municipal Landfill. Environmental Earth Sciences, 63, 1043-1055. http://dx.doi.org/10.1007/s12665-010-0780-3

[5] Abdullahi, N.K., Osazuwa, I.B. and Sule, P.O. (2011) Application of Integrated Geophysical Techniques in the Investigation of Groundwater Contamination: A Case Study of Municipal Solid Waste Leachate. Ozean Journal of Applied Sciences, 4, 7-25.

[6] Vargemezis, G., Tsourlos, P., Giannopoulos, A. and Trilyrakis, P. (2015) 3D Electrical Resistivity Tomography Technique for the Investigation of a Construction and Demolition Waste Landfill Site. Studia Geophysica et Geodaetica, 59, 461-476. http://dx.doi.org/10.1007/s11200-014-0146-5

[7] Said, R. (1962) Geology of Egypt. Elsevier, New York, 14.

[8] Hinze, W.J. and Zietz, I. (1985) The Composite Magnetic Anomaly Map of Conterminous United State. In: Hinze, W.J., Ed., The Utility of Regional Gravity and Magnetic Anomaly Maps, Society of Exploration Geophysicists, Tulsa, 1-24. http://dx.doi.org/10.1190/1.0931830346.ch1

[9] Lidiak, E.G., Hinze, W.J., Keller, G.R., Reed, J.E., Braile, L.W. and Johnson, R.W. (1985) Geologic Significance of Regional Gravity and Magnetic Anomalies in the East-Central Midcontinent. In: Hinze, W.J., Ed., The Utility of Re- 
gional Gravity and Magnetic Anomaly Maps, Society of Exploration Geophysicists, Tulsa, 287-307. http://dx.doi.org/10.1190/1.0931830346.ch22

[10] Yunsheng, S., Strangway, D.W. and Urquhart, W.E.S. (1985) Geologic Interpretation of a High-Resolution Aeromagnetic Survey, in the Amos-Barraute Area of Quebec. In: Hinze, W.J., Ed., The Utility of Regional Gravity and Magnetic Anomaly Maps, Society of Exploration Geophysicists, Tulsa, 413-425. http://dx.doi.org/10.1190/1.0931830346.ch31

[11] Yarger, H.L. (1985) Kansas Basement Study Using Spectrally Filtered Aeromagnetic Data. In: Hinze, W.J., Ed., The Utility of Regional Gravity and Magnetic Anomaly Maps, Society of Exploration Geophysicists, Tulsa, 213-232. http://dx.doi.org/10.1190/1.0931830346.ch18

[12] Cooper, G.R.J. and Cowan, D.R. (2006). Enhancing Potential Field Data Using Filters Based on the Local Phase. Computers \& Geosciences, 32, 1585-1591. http://dx.doi.org/10.1016/j.cageo.2006.02.016

[13] Khalil, M.H. (2012b) Magnetic, Geo-Electric, and Groundwater and Soil Quality Analysis Over a Landfill from a Lead Smelter, Cairo, Egypt. Journal of Applied Geophysics, 86, 146-159. http://dx.doi.org/10.1016/j.jappgeo.2012.08.004

[14] Bhattacharyya, B.K. (1965) Two-Dimensional Harmonic Analysis as a Tool for Magnetic Interpretation. Geophysics, 30, 829-857. http://dx.doi.org/10.1190/1.1439658

[15] Brigham, E.O. (1974) The Fast Fourier Transform. Prentice Hall, Englewood Cliffs.

[16] Bott, M.H.P. (1973) Inverse Methods in Interpretation of Gravity and Magnetic Anomalies. Methods in Computational Physics, 13, 133-162.

[17] Roberts, R.L., Hinze, W.J. and Leap, D.I. (1989) A Multi-Technique Geophysical Approach to Landfill Investigations, Proceeding of the 3rd National Outdoor Action Conference on Aquifer Restoration, Ground Water Monitoring and Geophysical Methods, Orlando, 22-25 May 1989, 797-811.

[18] Baranov, V. (1957) A New Method for Interpretation of Aeromagnetic Maps, Pseudo-Gravimetric Anomalies. Geophysics, 22, 359-363. http://dx.doi.org/10.1190/1.1438369

[19] Andreason, G.E. and Zietz, I. (1962) Limiting Parameters in the Magnetic Interpretation of a Geologic Structure. Geophysics, 27, 807-814. http://dx.doi.org/10.1190/1.1439104

[20] Mendonca, C.A. and Silvia, B.C. (1993) A Stable Truncated Series Approximation of the Reduction-to-the Pole Operator. Geophysics, 58, 1084-1090. http://dx.doi.org/10.1190/1.1443492

[21] Blakely, R.J. (1995) Potential Theory in Gravity \& Magnetic Applications. Cambridge University Press, Cambridge. http://dx.doi.org/10.1017/CBO9780511549816

[22] Baranov, V. and Naudy, H. (1964) Numerical Calculation of the Formula of Reduction to the Magnetic Pole. Geophysics, 29, 67-79. http://dx.doi.org/10.1190/1.1439334

[23] Macleod, I.N., Vieira, S. and Chaves, A.C. (1972) Analytical Signal and Reduction to the Pole in the Interpretation of Total Magnetic Field Data at Low Magnetic Latitudes. 3rd International Congress of the Brazilian Geophysical Society, Rio de Janeiro, 7 November 1993, 830-835.

[24] Bhattacharyya, B.K. (1966) Continuous Spectrum of the Total Magnetic Field Anomaly Due to a Rectangular Prismatic Body. Geophysics, 31, 197-212. http://dx.doi.org/10.1190/1.1439767

[25] Spector, A. and Grant, F.S. (1970) Statistical Models for Interpreting Aeromagnetic Data. Geophysics, 35, $293-302$. http://dx.doi.org/10.1190/1.1440092

[26] Cianciara, B. and Marcak, H. (1976) Interpretation of Gravity Anomalies by Means of Local Power Spectra. Geophysical Prospecting, 24, 273-286. http://dx.doi.org/10.1111/j.1365-2478.1976.tb00925.x

[27] Stefan, M. and Vijay, D. (1996) Depth Estimation from the Scaling Power Spectrum of Potential Fields. Geophysical Journal International, 124, 113-120. http://dx.doi.org/10.1111/j.1365-246X.1996.tb06356.x

[28] Ravat, D. (1996) Analysis of the Euler Method and Its Applicability in Environmental Investigations. Journal of Environmental and Engineering Geophysics, 1, 229-238. http://dx.doi.org/10.4133/JEEG1.3.229

[29] Hood, P.J., Holroyd, M.T. and Mcgrath, P.H. (1979) Magnetic Method Applied to Base Metal Exploration. In: Hood, P.J., Ed., Geophysics and Geochemistry in the Search for Metallic Ores, Ministry of Supply and Services Canada, Ottawa, 77-104.

[30] Keller, G.R., Smith, R.A., Hinze, W.J. and Aiken, C.L.V. (1985) Regional Gravity and Magnetic Study of West Texas. In: Hinze, W.J., Ed., The Utility Of Regional Gravity And Magnetic Anomaly Maps, Society of Exploration Geophysicists, Tulsa, 198-212. http://dx.doi.org/10.1190/1.0931830346.ch17

[31] Rose, T., Hambach, U. and Krumsiek, K. (1996) Preliminary Results of High Resolution Magnetic Susceptibility Measurements on the Research Cores Kirchrode I and II, Milankovitch Forced Sedimentation during the Upper Albian.

[32] Hoover, D.B., Williams, C., Williams, B. and Mitchell, C. (2008) Magnetic Susceptibility, a Better Approach to De- 
fining Garnets. Journal of Gemology, 31, 91-104. http://dx.doi.org/10.15506/JoG.2008.31.3.91

[33] Pesonen, L., Nevanlinna, H., Leion, M.A.H. and Ryno, J. (1994) The Earth’s Magnetic Field Maps of 1990. Geophysics, 30, 57-77.

[34] Zurflueh, E.G. (1967) Application of Two-Dimensional Linear Wavelength Filtering. Geophysics, 32, 1015-1035. http://dx.doi.org/10.1190/1.1439905

[35] Dean, W.C. (1958) Frequency Analysis for Gravity and Magnetic Interpretation. Geophysics, 23, 97-127. http://dx.doi.org/10.1190/1.1438457

[36] Roest, W.R. and Pilkington, M. (1993) Identifying Remnant Magnetization Effects in Magnetic Data. Geophysics, 58, 653-659. http://dx.doi.org/10.1190/1.1443449

[37] Leite, L.W.B. and Leao, J.W.D. (1985) Ridge Regression Applied to the Inversion of Two-Dimensional Aeromagnetic Anomalies. Geophysics, 50, 1294-1306. http://dx.doi.org/10.1190/1.1442000

[38] Boashash, B. (2003) Time-Frequency Signal Analysis and Processing: A Comprehensive Reference. Elsevier Science, Oxford.

[39] Naudy, H. (1971) Automatic Determination of Depth on Aeromagnetic Profiles. Geophysics, 36, 717-722. http://dx.doi.org/10.1190/1.1440207

[40] Reid, A.B., Allsop, J.M., Grasner, H., Millett, A.J. and Somerton, I.W. (1990) Magnetic Interpretation in Three Dimensions Using Euler Deconvolution. Geophysics, 55, 80-91. http://dx.doi.org/10.1190/1.1442774

[41] Thompson, D.T. (1982) A New Technique for Making Computer-Assisted Depth Estimates from Magnetic Data. Geophysics, 47, 31-37. http://dx.doi.org/10.1190/1.1441278

[42] Conyers, L.B. and Dean, G. (1997) Ground-Penetrating Radar. An Introduction for Archaeologists. AltaMira Press, Walnut Creek, London and New Delhi.

[43] Davis, J.L. and Annan, A.P. (1989) Ground Penetrating Radar for High-Resolution Mapping of Rock and Soil Staratigraphy. Geophysical Prospecting, 37, 531-551. http://dx.doi.org/10.1111/j.1365-2478.1989.tb02221.x

[44] Jol, H.M. (Ed) (2008) Ground Penetrating Radar Theory and Applications. Elsevier, Amsterdam.

[45] Rashed, M., Kawamura, D., Nemoto, H., Miyata, T. and Nakagawa, K. (2003) Ground Penetrating Radar Investigations across the Uemachi Fault, Osaka, Japan. Journal of Applied Geophysics, 53, 63-75. http://dx.doi.org/10.1016/S0926-9851(03)00028-4

[46] Meju, M.A. (2006) Geoelectrical Characterization of Covered Landfill. In: Vereecken, H., et al., Eds., Applied Hydrogeophysics, Springer Verlag, Berlin, 319-339.

[47] Khalil, M.H. (2012) Reconnaissance of Freshwater Conditions in a Coastal Aquifer. Synthesis of 1D Geoelectric Resistivity Inversion and Geohydrological Analysis. Near Surface Geophysics, 10, 427-441. http://dx.doi.org/10.3997/1873-0604.2012036

[48] Leila, D., Djamel, M., Jean-Luc, C., Abdesslam, A., Rabah, B., Mehdi, A.G., Bertrand, G., Amar, B. and El-Hadi, O. (2010) Evidence for an Underground Runoff and Soil Permeability at the Ouled Fayet (Algiers, Algeria) Subsurface Landfill Pilot Project from Geophysical Investigations. Environmental Earth Sciences, 59, 1149-1158. http://dx.doi.org/10.1007/s12665-009-0105-6 